\title{
Explaining adoption and use of payment instruments by U.S. consumers
}

\author{
Sergei Koulayev \\ Marc Rysman \\ Consumer Financial Protection Bureau Boston University \\ Scott Schuh Joanna Stavins \\ Federal Reserve Federal Reserve \\ Bank of Boston Bank of Boston*
}

May 26, 2015

\begin{abstract}
Motivated by recent policy intervention into payments markets that can lead to changes to the prices that consumers face for different payment instruments, this paper develops and estimates a structural model of adoption and use of payment instruments by U.S. consumers. We utilize a cross-section from the Survey of Consumer Payment Choice, a new survey of consumer behavior. Our structural model emphasizes the distinction between the adoption and use of a payment instrument. We evaluate substitution among payment instruments, as well welfare implications. We find that cash is the most significant substitute to debit cards in retail settings, whereas checks are the most significant in bill-pay settings. Furthermore, we find low income consumers lose proportionally more than high income consumers when debit cards become more expensive, whereas the reverse is true when credit cards do.
\end{abstract}

\footnotetext{
${ }^{*}$ We thank Wilko Bolt, Beth Kiser, Ariel Pakes and Bob Triest for insightful comments on the paper. We also thank Mingli Chen, Vikram Jambulapati, Sarojini Rao, and Hanbing Zhang for excellent research assistance. The comments of the editor and two anonymous referees greatly improved the paper. The views presented here are those of the authors only and do not necessarily represent the views of the Federal Reserve Bank of Boston, Federal Reserve System or the Consumer Financial Protection Bureau.
} 


\section{Introduction}

The goal of this paper is to estimate substitution patterns between payment instruments for U.S. consumers. We analyze substitution in response to change in both the value of usage and the cost of adoption of payment instruments. This issue is important because, during the past three decades, the U.S. payments system has been undergoing a transformation from paper to electronic means of payment. Modern consumers have access to ATM machines, debit and prepaid cards, and online banking. Because governments have a responsibility to deliver a safe and efficient payments system, understanding substitution patterns is important. More specifically, our research is motivated by recent regulation of the debit card interchange fee, further described below, that has the potential to make debit cards less attractive to consumers, either via bank-imposed usage charges or adoption charges. Recent regulation also allows merchants to surcharge for cards. Understanding how consumers will substitute in response to these changes is important for evaluating the impact of these policies.

Our paper makes use of a new public data set, the Survey of Consumer Payment Choice (SCPC, described in Foster, Meijer, Schuh, and Zabek 2009) specifically designed to address these topics. In the SCPC, participants report their number of transactions that month by payment instrument: cash, check, credit and debit, prepaid cards, online banking, direct bank account deductions, and direct income deductions. In addition, for each instrument, the participant indicates how many transactions were used in each payment context, such as traditional retail, online retail, and bill-pay. The data set also includes information about participant demographics such as age, income and education. The survey asks respondents to evaluate instruments, on a numerical scale, along several dimensions, such as security, ease of use, and set-up cost, which turn out to be important predictors of choice. A drawback of the SCPC is that it does not track transaction values, so our model studies only the number of transactions, not the values.

In order to estimate substitution patterns, this paper develops and estimates a new structural model of adoption and use of payment instruments. In our twostage model, consumers first adopt a portfolio of payment instruments, such as debit, credit, cash and check. Then, consumers choose how much to use each instrument in different contexts, such as online, essential retail, and nonessential retail. The model 
has several important technical features. A strength of our model is that it allows for flexible substitution patterns. Our model allows for correlation in unobserved terms both across instruments and contexts, so for instance, one consumer may prefer to use a credit card both in on-line and retail payments, whereas another may prefer to shop on-line, whether it be with a credit card or a debit card. We further allow for correlation to affect both adoption and usage for a given instrument, which thus allows for a selection effect: consumers who adopt an instrument for unobserved reasons may also have high usage of that instrument for unobserved reasons. Since consumers in the adoption stage perceive a portion of the terms in usage that are unobserved to the researcher, our model allows consumers to know more than the researcher about their usage when the consumers make their adoption decisions. We believe this is an attractive and realistic feature in the adoption of payments instruments. Since usage value and adoption cost are modeled in a simultaneous equations framework, we use exclusion restrictions based on consumer ratings of instruments to achieve 15 identification. Our model generates a computationally complex likelihood function, which we address with simulation techniques.

Our counterfactual analysis considers what would happen if debit cards became more expensive to use or adopt. We find that cash and check are significant substitutes for debit cards, more so than credit cards. These results differ by context - cash is 20 a popular substitute in retail whereas checks are a popular substitute in bill-pay contexts. The coverage of bill payments is unusual for data sets in the payments area, and we find that accounting for bill payments is important. Overall, we find regulation that makes debit cards less attractive to consumers, either to adopt or to use, moves consumers away from digital payment products such as credit cards. This 25 effect differs across demographics: We find that making debit cards less attractive causes high-income and high-education consumers to substitute towards credit cards relatively more than low-income and low-education consumers, who tend to move towards paper products, such as cash and check. Similar to debit, we find that making credit cards less attractive causes substantial substitution to paper products, although less so than in the case of debit.

We also perform welfare calculations. We find that when debit becomes less attractive, less wealthy consumers suffer relatively more, as they use debit more intensively and may not have access to as many alternative instruments. In contrast, making credit cards less attractive causes wealthy consumers to suffer relatively more, 
as they are more likely to hold and use credit cards.

These results are important for the Board of Governors of the Federal Reserve Bank, which was mandated by the Financial Reform Act of 2010 to regulate debit card interchange fees, leading to a substantial reduction in the overall fee level. Since wards paper products, the regulation may increase the cost of the payments system. Furthermore, our result that regulating credit and debit cards have different effects for different income groups implies that these policies have distributional implications, and thus adds a further concern to policy intervention. Note that we do not provide a full welfare calculation of all of the implications of these regulations, such as how banks will pass through changes in the interchange fee or how merchants will respond. Although we do not evaluate the policies overall, our paper contributes to this evaluation.

\section{Policy setting and Literature Review}

Understanding consumer substitution patterns between payment instruments is an important policy issue. Consumers face few explicit costs of using an instrument, and so consumers may receive poor signals about the social cost of their choice. For this reason, and a variety of others, government intervention is common in these markets, and understanding substitution patterns is important for designing and evaluating these policies. For example, central banks typically consider payment cards to be more efficient than cash or check, since payment cards are a digital mechanism. In this light, the effect of regulation that lowers the value of debit cards depends on whether consumers switch to cash or to credit cards. Furthermore, substitution patterns may depend on whether the regulation affects the adoption cost or usage value of debit cards, so it is important to employ an approach that recognizes these differences.

Our emphasis on debit and credit cards is in part motivated by two recent policy actions in the payments market. First, in the United States, recent legislation requires 
the Federal Reserve to regulate the interchange fees of debit cards. ${ }^{1}$ Note that regulation is common internationally: Australia has regulated credit card interchange fees since 2003, the European Union has recently implemented caps on some interchange fees, and a number of other countries are at various stages of regulation (Bradford and

5 Hayashi 2008; Weiner and Wright 2005). As banks respond to this regulation, consumers may face different charges for adoption and use of payment instruments. ${ }^{2}$ We do not study bank pricing in this paper. Rather, we consider how consumers would respond to different potential changes in the fee structure of banks. In particular, we use our model to simulate how consumers respond to a change in the usage value and to a change in the adoption cost of debit cards. These simulations are meant to represent cases in which banks pass their reductions in interchange revenue through to consumers either via lowering usage value (such as eliminating reward programs) or via increased adoption costs (such as fixed fees for holding a debit card).

A second policy development is the move towards allowing merchants to surcharge or discount payment instruments. Previously, merchant contracts with card companies prohibited merchants from steering consumers among card products, although merchants have always been allowed to offer discounts for cash use. A series of recent antitrust and regulatory initiatives allow for merchants to discount particular card

\footnotetext{
${ }^{1}$ This regulation is part of the Dodd-Frank Wall Street Reform and Consumer Protection Act, signed into law in July, 2010. The specific section referring to debit interchange fees is often referred to as the Durbin Amendment. It requires the Federal Reserve to regulate the interchange fees on debit cards based on bank variable costs. The current policy, which became effective on October 1, 2011, sets the fee substantially below previously observed interchange fees, particularly for signature debit cards. See the Board of Governors' final rule, Regulation II, Debit Card Interchange Fees and Routing (http://www.federalreserve.gov/newsevents/press/bcreg/20110629a.htm)

${ }^{2}$ In the United States, some banks have responded to the debit interchange regulation by eliminating rewards programs, a change in the usage value. Some banks have proposed fixed monthly charges on holding or using a debit card, a change in the adoption cost. For instance, Bank of America proposed a fee of $\$ 5$ in each month in which a debit card was used. This well-publicized initiative was eventually abandoned, but alternatives, such as monthly fees on checking accounts, can be regarded in a similar way.
} 
products. $^{3}$ Also, surcharging is currently allowed in some countries, such as Australia and the United Kingdom, and appears to impact card usage. Since discounting and/or surcharging appears to be likely in the United States in the near future, we are interested in how consumers will respond. Thus, we interpret our experiments with the usage value of credit cards in this light.

Discussing policy brings us to several caveats. Keep in mind that our paper addresses only some of the issues associated with interchange and surcharging regulation. We do not incorporate the merchant response to such regulation either in terms of acceptance or pricing, and we do not study the ways in which regulation will affect bank pricing or consumer banking choices. Also, other recent policy changes, such as changes in the ability of merchants to steer payments over different card networks, also affect these outcomes. Conditional on these factors, our model is able to provide an estimate of substitution patterns, which has an important role in welfare outcomes.

Our paper contributes to several literatures, both in terms of modeling and in its application. As our econometric model allows consumers to make separate decisions about adoption and use, it is related to the "discrete-continuous" (or "discretediscrete") literature of Dubin and McFadden (1984) and Hendel (1999), as well as the selection literature of Heckman (1979). Relative to these models, our model combines two desirable features. As in the selection literature, our model allows consumers to know more than the econometrician about usage at the time of adoption. We implement this by allowing for correlation between the unobserved terms in usage and adoption. As in the structural discrete-continuous literature, we structurally estimate the effect of the usage value on adoption. Our model incorporates both of these features in a single model, which we discuss further below. ${ }^{4}$

25 One aspect of our model is the choice between bundles of payments instruments (for instance, consumers may choose debit, credit, both, or neither), so our model is

\footnotetext{
${ }^{3}$ A July, 2011 settlement between the Department of Justice and Visa and MasterCard (effective January, 2013) allows merchants to discount card products at the point of sale, so a merchant could offer a discount to a consumer for using a debit or credit card that sets low merchant fees. A separate settlement proposed in July, 2012 between merchants and Visa and MasterCard would allow merchants to surcharge different card products, rather than offer a discount (there is little difference between surcharging and discounting in standard economic models, but the difference might be important from a behavioral perspective and appears to be important to industry participants.). Furthermore, the Durbin Amendment (see footnote 1) also allows for discounting. For some discussion, see Schuh, Shy, Stavins, and Triest (2012).

${ }^{4}$ As discussed below, other models, such as structural labor models and some models in environmental economics and trade, have similar features, although they do not highlight these issues.
} 
related to the bundled choice literature such as Gentzkow (2007) and Crawford and Yurukoglu (2012). When observing choices over bundles, it is difficult to distinguish between complementary products and correlated preferences. Gentzkow (2007) addresses this issue using an instrumental variables approach. In contrast, we exploit (or complementarity) between payment instruments, and we allow for only correlation in the adoption stage (which is similar to the approach of Crawford and Yurukoglu 2012).

There is a substantial literature on consumer payment choice, such as that reviewed in Rysman (2007; 2010). Schuh and Stavins $(2010 ; 2013)$ are related to our paper in that they use a Heckman selection model of each payment instrument separately to study adoption and use. Our paper uses a more structural model of the joint adoption and use decision, along with the focus on elasticities in the context of regulatory intervention into pricing in payments markets. Ching and Hayashi (2010)

15 measure how payment choice responds to reward programs. Like, Schuh and Stavins (2010; 2013), Ching and Hayashi (2010) precedes our paper in the use of self-reported preference data to account for heterogeneity in consumer preferences. Our paper is closely related to the work of Borzekowski, Kiser, and Ahmed (2008) and Borzekowski and Kiser (2008), which use survey data to study adoption and use of debit. Arango, Huynh, and Sabetti (2015) also study payment choice, in this case using diary data. Amromin and Chakravorti (2009) study cash use across different countries. Klee (2008) and Cohen and Rysman (2012) study payment choice in grocery setting using scanner data. Wang and Wolman (2014) study payment card use with data collected from the registers of a large retailer. As in Yang and Ching (2014), Hayashi and Klee 25 (2003) study the adoption of payment instruments as a form of technology adoption. Bolt, Jonker, and Van Renselaar (2010) study payments in the context of surcharging. Our model is distinguished from other work in that we consider the joint adoption and usage of multiple instruments simultaneously. Numerous central banks now collect data similar to ours, so a further contribution of our paper is to provide a method for analyzing this kind of data.

Our paper is relevant for the literature on two-sided markets as well (see Rochet and Tirole 2006; Rysman 2009; Hagiu and Wright 2015). While we do not model two-sidedness in the sense that we do not consider the response of merchants to consumer decisions, the payments context that we study is an important motivator for 
the two-sided markets literature. Also, the distinction between adoption and use decisions that we focus on is often important in that literature. Examples are Rochet and Tirole (2006) and Weyl (2010). There is a substantial literature studying interchange fees, such as Rochet and Tirole (2002). See Verdier (2011) and Rysman and Wright

5 (2015) for recent surveys. As we are motivated by regulatory and antitrust intervention into payment markets, our research is related to a group of papers that observe such interventions directly and estimate the impact. These papers typically have less detailed data or modeling of the consumer side, but a more complete treatment of the merchant side and thus, the two-sided effect. Examples from the Spanish bank10 ing market are Carbo-Valverde, Chakravorti, and Rodriguez-Fernandez (2015) and Carbo-Valverde, Linares-Zegarra, and Rodriguez-Fernandez (2012). Schuh, Stavins, and Shy (2010) model the welfare implications of an interchange fee system that rewards card users relative to non-card users.

\section{Data}

Our paper relies on the Survey of Consumer Payment Choice (SCPC). This data set is designed by the Consumer Payments Research Center at the Federal Reserve Bank of Boston and collected by the RAND Corporation. The SCPC uses the RAND American Life Panel, a pool of individuals who are frequently surveyed on a variety of topics. The respondents complete Internet surveys, with special provisions for respondents without Internet access. Several preliminary surveys have been administered, but we use the first installment of the annual survey, which was administered in 2008. The data are publicly available.

The SCPC focuses on adoption and use of different payment instruments in retail and billing environments, as well as cash holdings and online banking. In addition, the survey collects consumer attitudes towards different features of payment instruments, as well as demographic information. A more complete description of the data set, as well as a useful set of summary variables, appears in Foster et al. (2009). Below, we present a few tables that are relevant to our goals. The SCPC provides survey weights for obtaining a nationally representative sample. We use the weights to construct the tables in this section and the summary statistics in Section 8, but not to estimate the model parameters, as reported in Section $7 .{ }^{5}$ To restrict heterogeneity, we drop from

\footnotetext{
${ }^{5}$ If our model of heterogeneity is well specified, there will be no difference between estimates with
} 
our sample consumers who do not have checking accounts, leaving 997 observations. For this reason, the weighted national estimates reported here will not match exactly the published SCPC results in Foster et al. (2009).

The survey asks consumers about adoption and use of eight payment instruments: 5 cash, checks, debit cards, credit cards, prepaid cards, online banking bill payment, bank account deduction, and income deduction. ${ }^{6}$ Table 14 in the Appendix provides a detailed explanation of each payment instrument. Briefly, debit cards draw payment immediately from the consumer's bank account. Credit cards draw from a consumer credit line that can be paid monthly or rolled over to future months with some finance charge. In our classification system, credit cards include charge cards, which are cards for which the balance must be paid monthly, and do not have the month-tomonth credit feature. Prepaid cards allow a consumer to load a dollar value of money (prefunded by cash, a demand deposit account, or even another payment card) and then make payments wherever the card is accepted, up to the amount that is preloaded on to the card. Some prepaid cards work only with a particular merchant, or just for transportation, whereas others can be used as general purpose payment cards. With online banking bill-pay, the consumer uses her bank web site to direct a payment to a service provider or an individual. With bank account deduction, the consumer provides her bank account information to a service provider, and the service provider communicates with the bank to collect the fee. ${ }^{7}$ Thus, bank account deduction differs from online banking bill payment primarily by the initiation and authorization of the payment through disclosure of the account and routing numbers, which may be a security concern, and by the entity given authorization to make the electronic payment (bank versus third party). Both of these electronic payments are functionally similar except that online banking bill payment must occur on the bank's website while bank account deductions can be made on the website of a billing company such as a utility or an online retailer such as Amazon. ${ }^{8}$ Both of these

and without the weights. As we include many interactions with demographics, weighted results can be difficult to interpret.

${ }^{6}$ The SCPC also includes data on money orders and travelers checks. However, it does not include characteristics of these instruments and consumers use them infrequently, so we do not include them in our analysis.

${ }^{7}$ The official term in the 2008 SCPC is "electronic bank account deduction" but we suppress "electronic" for simplicity. In the 2009 and later SCPC, the official terminology changed to "bank account number payment."

${ }^{8}$ Note that the 2008 SCPC did not allow consumers to choose that they used online banking to do automatic bill-pay. This combination will be allowed in future versions of the survey. 


\begin{tabular}{|c|c|c|c|c|c|c|}
\hline Paper & & Card & & \multicolumn{3}{|c|}{ Bill pay only } \\
\hline Cash Check & Debit & Credit & Prepaid & $\begin{array}{l}\text { On-line } \\
\text { banking }\end{array}$ & $\begin{array}{c}\text { Bank accnt } \\
\text { deduct }\end{array}$ & $\begin{array}{l}\text { Income } \\
\text { deduct }\end{array}$ \\
\hline $100 \% \quad 100 \%$ & $80 \%$ & $78 \%$ & $17 \%$ & $52 \%$ & $73 \%$ & $18 \%$ \\
\hline
\end{tabular}

Table 1: Adoption rates by payment instrument.

electronic methods can be used to set up automatic payments for recurring bills, such as mortgages, or to make discretionary payments as needed. Direct deduction from income designates payments that come directly out of a consumer's paycheck and must be organized with the employer. Health insurance payments are a common example of direct deduction from income. Table 1 reports adoption rates for each payment type in our sample. Adoption of cash and check is 100 percent by assumption due to sample selection of bank account holders. ${ }^{9}$

In addition to average adoption numbers, it will be important to analyze which instruments are typically held together. Table 2 reports the top 15 most popular bundles of instruments. The first column reports the share of the population that holds that bundle (making use of the population weights in the data set). Each column has a "1" or a "0" for whether that instrument is in the bundle or not. For example, the most popular bundle, held by $23 \%$ of the population, includes cash, check, debit, credit, on-line banking and bank account deduction, missing only prepaid and income deduction, for a total of six payment instruments. The fourth most popular bundle, held by $6 \%$ of the population, has cash and check and no other instruments. Near the bottom of the table, we see consumers that hold either debit or credit, but not both. This table covers $84.7 \%$ of the population.

In addition to the adoption of payment mechanisms, the survey collects data on the use of payment instruments. The survey asks participants how many transactions they complete in a typical month with each payment instrument in seven payment contexts.

\footnotetext{
${ }^{9}$ Note that adoption of debit is only $80 \%$, although banks seek to distribute ATM cards with debit payment features. Thus, after opening an account, there is rarely any further "adoption" action that must take place to obtain a debit card. This number is below $100 \%$ because some people tell their bank that they do not want a debit card. Also, some people may not recognize that they have a debit card and misreport. Interestingly, the $80 \%$ number is consistent with our discussion with bank executives, who have access to administrative data. Overall, we expect debit cards to have low adoption costs, and we ultimately find that they have the lowest adoption costs of all of our instruments for low income consumers (note that we consider only households that have a bank account).
} 


\begin{tabular}{|c|c|c|c|c|c|c|c|c|}
\hline Population & Cash & Check & Debit & Credit & Prepaid & $\begin{array}{c}\text { Online } \\
\text { banking }\end{array}$ & $\begin{array}{c}\text { Bank accnt } \\
\text { deduction }\end{array}$ & $\begin{array}{l}\text { Income } \\
\text { deduction }\end{array}$ \\
\hline $23 \%$ & 1 & 1 & 1 & 1 & 0 & 1 & 1 & 0 \\
\hline $12 \%$ & 1 & 1 & 1 & 1 & 0 & 0 & 1 & 0 \\
\hline $8 \%$ & 1 & 1 & 1 & 1 & 0 & 1 & 1 & 1 \\
\hline $6 \%$ & 1 & 1 & 0 & 0 & 0 & 0 & 0 & 0 \\
\hline $5 \%$ & 1 & 1 & 1 & 1 & 1 & 1 & 1 & 0 \\
\hline $4 \%$ & 1 & 1 & 1 & 1 & 0 & 1 & 0 & 0 \\
\hline $4 \%$ & 1 & 1 & 1 & 1 & 0 & 0 & 0 & 0 \\
\hline $3 \%$ & 1 & 1 & 1 & 0 & 0 & 0 & 1 & 0 \\
\hline $3 \%$ & 1 & 1 & 1 & 1 & 1 & 0 & 1 & 0 \\
\hline $3 \%$ & 1 & 1 & 1 & 1 & 0 & 0 & 1 & 1 \\
\hline $3 \%$ & 1 & 1 & 0 & 1 & 0 & 0 & 0 & 0 \\
\hline $3 \%$ & 1 & 1 & 0 & 1 & 0 & 0 & 1 & 0 \\
\hline $2 \%$ & 1 & 1 & 1 & 0 & 0 & 1 & 1 & 0 \\
\hline $2 \%$ & 1 & 1 & 1 & 0 & 0 & 1 & 0 & 0 \\
\hline $2 \%$ & 1 & 1 & 1 & 0 & 0 & 0 & 0 & 0 \\
\hline
\end{tabular}

A "1" indicates population holds that instrument. Percentages are unweighted. Number of observation: 997.

Table 2: Population holdings of the top 15 bundles of payment instruments.

The contexts are: essential retail, non-essential retail, online retail, automatic bills, online bills, bills by check or in-person, and other nonretail. Essential retail and non-essential retail goods both refer to in-person shopping only. All online purchases are captured by online retail. Automatic bills involve a consumer agreeing with a 5 merchant to pay some amount on a regular basis. For example, many consumers pay their mortgage and utility bills this way. Online bills involve a consumer going to a website (other than the consumer's online banking site) to pay a bill. Bills by mail or in person involve a consumer paying a bill by mailing a check or card information, or by visiting the merchant in person. Other nonretail includes payments to household help, such as baby-sitters, person-to-person gifts and loans, and similar transactions not included in the aforementioned categories.

It is worth taking a moment to understand the definitions of the essential and non-essential retail contexts. While these are meant to be similar to the distinction between necessities and luxury goods, the survey operates at the level of the transaction, not the product, and so the survey asks about the type of store rather than the product purchased. The survey in fact does not use the essentiail/non-essential terminology. The survey asks participants to determine how many payments they make 
for retail basic goods in-person. The survey lists a set of examples, which are grocery stores, supermarkets, food stores, restaurants, bars, coffee shops, superstores, warehouses, club stores, drug or convenience stores, and gas stations. The survey then asks the participant to determine how many payments they make for other retail goods electronics and appliances stores, home goods, hardware stores, furniture stores, office supply stores, and other miscellaneous and specialty stores. We term these two sets of payments as essential and non-essential, but it is not perfect terminology. ${ }^{10}$

Table 3 reports the average number of transactions by context in our sample, as well as by instrument and context. Blank entries in Table 3 indicate entries that were ruled out by the survey itself, such as using cash to shop on-line. We see that cash and debit are popular for essential retail, whereas credit is relatively more popular for nonessential retail. Check use is concentrated in bill-pay, relative to credit and debit. But debit, credit and bank account deduction are also popular in bill-pay, with numbers of transactions close to check. Check dominates the mail-in and in-person context, whereas bank account deduction is the most popular method for automatic and online bill-pay. As we will see below, these features of the data play an important role in our results. Naturally, not every payment instrument is available in every payment context; for instance, one cannot shop online with cash. Our econometric model provides predictions of the outcomes in Table 1 and Table $3 .{ }^{11}$

It is important to recognize that the SCPC records only the number of transactions with each instrument, not the value of those transactions. Clearly, the value of transactions is also of interest. However, it is outside of the scope of this paper. Much of the private and social costs of using a payment instrument are at a per 25 transaction level, not a per dollar level. For evidence, see Garcia Swartz, Hahn, and Layne-Farrar (2006). Thus, we view the transaction level with great interest.

Importantly for our purposes, the SCPC asks participants about how they evaluate

\footnotetext{
${ }^{10}$ In particular, we do not mean to take a position on what products are considered essential for modern life. We might view a cellular phone purchased at an electronics store as essential, or a bottle of wine purchased as part of a grocery shop as non-essential. But if consumers pay for the phone as they would for a non-essential payment and the grocery shop with wine as they would for an essential payment, it causes little problem for us.

11 Table 3 implies that the total number of transactions in a month is 68.6. This number is difficult to verify in other data sets. Interestingly, a recent diary-based survey of payment habits administered to the same population found a similar total number of transactions. For more on the Diary of Consumer Payment Choices, see Shy and Stavins (2014).
} 


\begin{tabular}{|c|c|c|c|c|c|c|c|c|c|}
\hline & \multicolumn{3}{|c|}{ Bill Pay } & \multicolumn{3}{|c|}{ Retail } & \multirow[b]{2}{*}{ Other } & \multirow[b]{2}{*}{ Total } & \multirow[b]{2}{*}{ Share } \\
\hline & $\overline{\text { Automatic }}$ & Online & In person & Online & Essential & Non-essential & & & \\
\hline Cash & & & 1.1 & & 6.2 & 3.1 & 3.8 & 14.2 & $21 \%$ \\
\hline Check & & & 4.0 & 1.6 & 1.0 & 0.7 & 2.8 & 10.1 & $15 \%$ \\
\hline Debit card & 1.6 & 1.6 & 1.3 & 2.1 & 7.5 & 3.6 & 3.3 & 21.0 & $31 \%$ \\
\hline Credit card & 1.4 & 1.1 & 1.2 & 1.6 & 4.2 & 2.2 & 2.8 & 14.5 & $21 \%$ \\
\hline Prepaid card & & & & 0.1 & 0.2 & 0.1 & 0.1 & 0.5 & $1 \%$ \\
\hline Online banking & & 2.1 & & & & & & 2.1 & $3 \%$ \\
\hline Bank acct. deduct & 2.3 & 1.7 & & 1.3 & & & & 5.4 & $8 \%$ \\
\hline Income deduction & 0.8 & & & & & & & 0.8 & $1 \%$ \\
\hline Total & 6.0 & 6.5 & 7.6 & 6.8 & 19.1 & 9.8 & 12.8 & 68.6 & \\
\hline
\end{tabular}

Table 3: Number of Transactions Per Month by Payment Instrument and Context.

\begin{tabular}{lcccccccc} 
& Security & Setup & Accept & Cost & Control & Records & Speed & Ease \\
\hline Cash & 2.6 & 4.3 & 4.6 & 4.3 & 3.9 & 2.5 & 4.3 & 4.1 \\
Check & 2.9 & 3.7 & 3.6 & 3.7 & 3.2 & 4.1 & 2.9 & 3.4 \\
Debit card & 2.9 & 3.9 & 4.3 & 3.8 & 3.6 & 4.0 & 4.0 & 4.2 \\
Credit card & 3.0 & 3.7 & 4.5 & 2.7 & 3.5 & 4.2 & 4.0 & 4.3 \\
Prepaid card & 2.7 & 3.4 & 3.8 & 3.3 & 3.3 & 2.9 & 3.7 & 3.7 \\
Bank acct. deduct & 3.3 & 3.4 & 3.2 & 3.7 & 3.6 & 3.9 & 3.8 & 3.6 \\
\hline
\end{tabular}

997 observations, adjusted by population weights. The survey does not distinguish between on-line banking bill payment and automatic back account deduction for this part.

Table 4: Average Ratings of Payment Instruments.

payment mechanisms in several dimensions on a scale of 1 to 5 . Averages appear in Table 4. Higher numbers mean that the participant has a more favorable view. For instance, cash does poorly in security and records (the ease of tracking use) but well in set-up (the cost of obtaining or setting up a payment instrument), cost (the cost 5 of use) and acceptance (the level of merchant acceptance). The rest of the table is also consistent with conventional wisdom. For instance, checks score low on speed but high on record keeping. Debit and credit look similar to each other, except for cost, where debit is better. ${ }^{12}$

Our model simultaneously predicts adoption and usage, which raises an identification problem. For example, we may observe that consumers with high usage value are likely to adopt an instrument, but it will be difficult to say whether high usage value causes consumers to adopt an instrument or is instead correlated with adoption preference. Thus, there is a simultaneous equations problem, which we resolve with

\footnotetext{
${ }^{12}$ For consumers that revolve a credit card balance, they begin interest payments as soon as they make a purchase, so credit is indeed more costly for them. According to the Survey of Consumer Finances of 2013, 38.1\% of households revolve credit card balances.
} 


\begin{tabular}{|c|c|c|c|c|c|c|c|c|}
\hline & Security & Setup & Acceptance & Cost & Control & Records & Speed & Ease \\
\hline Security & 1.35 & & & & & & & \\
\hline Setup & 0.16 & 0.69 & & & & & & \\
\hline Acceptance & 0.14 & 0.38 & 0.68 & & & & & \\
\hline Cost & 0.22 & 0.34 & 0.26 & 1.02 & & & & \\
\hline Control & 0.11 & 0.24 & 0.25 & 0.22 & 1.36 & & & \\
\hline Records & 0.23 & 0.31 & 0.35 & 0.27 & 0.23 & 0.85 & & \\
\hline Speed & 0.15 & 0.37 & 0.37 & 0.30 & 0.25 & 0.32 & 0.68 & \\
\hline Ease of use & 0.17 & 0.45 & 0.47 & 0.38 & 0.26 & 0.38 & 0.50 & 0.74 \\
\hline
\end{tabular}

Table 5: Covariance matrix for ratings of debit cards.

exclusion restrictions - variables that can affect use but not adoption, and vice versa. We assume the rating of set-up cost affects adoption, but does not otherwise affect usage. We assume that the rest of the characteristics affect usage but not otherwise adoption. Thus, if we see that consumers who find an instrument easy to use are 5 particularly likely to adopt, than our exclusion restriction imposes that usage has a causal effect on adoption.

In practice, ease of use and cost of use turn out to be important in predicting usage. In order for these variables to be useful instruments, one requirement is that they vary substantially across the population. The significant results in the final tables confirm this, but for exploratory purposes, we also provide Table 5 . In this table, we calculate the covariance matrix for the ratings of debit cards. The diagonal provides the variance, whereas the off-diagonals are correlation coefficients (thus, they are between -1 and 1). Looking at the diagonal, we see substantial variance in ratings. Several have variances above 1 (on a 5 point scale) and all have variances above 0.5. In addition, the table indicates that none of the variables have correlations above 0.5, which suggests substantial heterogeneity in these ratings across the population. Tables for other payment instruments look similar.

\section{Model}

In this section, we present a model of consumer choice of adoption and use of payment instruments. Our model proceeds in two stages. In stage 1, the consumer picks which payment instruments to adopt. In stage 2 , the consumer faces payment opportunities and decides to allocate those opportunities to available instruments and contexts. That is, the consumer first picks adoption, and then use. 
In stage 1 , consumer $i$ chooses among $J$ payment instruments. Examples of instruments $j=1, \cdots, J$ are cash, credit card, and debit card. The consumer can adopt any combination of instruments. The consumer selects bundle $b_{i} \in B$, where $b_{i}$ is a set of payment instruments, and $B$ is the set of all possible sets of payment instrualways adopt cash and check (and we select our sample on this criteria), so there are only six choices; thus, $B$ has 64 elements $\left(2^{6}\right)$. Also, every bundle $b_{i}$ contains option $j=0$, which gives the consumer the option to not make a payment in the usage stage (stage 2). Before further describing the choice in stage 1, we describe stage 2 .

In stage 2 , consumer $i$ faces a sequence of $L$ payment opportunities, indexed by $l$. A payment opportunity is bestowed exogenously and gives a consumer the opportunity to make a purchase or pay a bill. At each payment opportunity $l$, the consumer chooses from $b_{i}$ which payment instrument to use, which may be the choice to forgo the payment opportunity. One can think of payment opportunities as time periods in the month, such as hours, as if the consumer could make one payment per hour. At each opportunity, the consumer selects which payment instrument to use and to which context to allocate the opportunity. For the instrument, the consumer selects one element $j \in b_{i}$. For the context, the consumer faces $C$ contexts. Examples of contexts, $c=1, \cdots, C$ are online purchases, essential retail, and nonessential retail, for a total of seven $(C=7)$ possible contexts. At each payment opportunity, each consumer selects from one of the seven contexts - all contexts are always available. The consumer can also choose not to use an opportunity, and thus make no payment, denoted as choosing $j=0$.

As an example, consider a single day in which a consumer is endowed with 12 25 payment opportunities (one per hour). The consumer may choose to skip the first two, buy an essential retail good with cash for the third, skip the next one, pay a bill by check with the fourth, skip the next three, buy a product online with a credit card with the next (assuming the consumer has adopted a credit card), and skip the remaining three opportunities in the day. Since we observe only the number of transactions in a month, we do not dwell on the ordering of transactions or how opportunities are spread over the day or month, and we assume that all payment opportunities are identical.

Our approach has several advantages. Our set-up makes use of the total number of payments to infer demand for payments relative to the outside option, which may be 
affected by their income, their preferences, or their portfolio of payment instruments (such as holding a credit card). For example, if income affects each instrument in a positive way, that tells us that high-income consumers make more payments than low-income consumers. An important issue is that credit cards have a credit function that can allow consumers to have more transactions relative to their income. Our model can match this by finding a large coefficient on a dummy variable for credit cards in the usage equation.

Also, our model allows consumers to substitute across contexts based on payment instruments. For instance, a consumer with a credit or debit card can choose to make online purchases, while a consumer with only cash and check cannot do so. As a result, a consumer with a card may choose fewer nonessential retail payments and more on-line payments. In practice, we assume that the number of payment opportunities $L$ is 390 per month, about 13 per day, constant across all consumers. This number is above what we observe for any consumer in the data set, and well above the average number of transactions. Thus, if we observe a consumer that makes 100 transactions in a month, we assume they chose not to make a transaction 290 times. ${ }^{13}$ Our model predicts the probability of transacting, as well as the probability of each instrument-context combination for each transaction.

At opportunity $l$, the utility to consumer $i$ from using payment method $j \in b_{i}$ and context $c$ is:

$$
u_{i j c l}=\delta_{i j c}+\varepsilon_{i j c l}^{u} .
$$

The consumer observes both $\delta_{i j c}$ and $\varepsilon_{i j c l}^{u}$ when choosing $j$ and $c$, but observes only $\delta_{i j c}$ at the time of adopting $j$. Thus, $\varepsilon_{i j c l}^{u}$ can be interpreted as prediction error in usage at the time of adoption (the superscript $u$ refers to use). Discussion of econometrics is delayed until the following section, but we note that the econometrician 25 may not perfectly observe $\delta_{i j c}$, so the consumer still knows more about usage than the econometrician at the time of adoption. For each opportunity $l$, consumer $i$ chooses $j$ and $c$ such that $u_{i j c l} \geq u_{i j^{\prime} c^{\prime} l} \forall j^{\prime} \in b_{i}, c^{\prime}=1, \ldots, C$. Throughout the paper, we refer to $\delta_{i j c}$ as the usage value of instrument $j$ to consumer $i$ in context $c$.

\footnotetext{
13 The choice of $L$ is analogous to selecting the size of the potential market in typical discrete choice models, such as Berry, Levinsohn, and Pakes (1995) and Nevo (2001). In many data sets, we observe market shares among the available products but we do not observe how many people might have purchased but selected not to. In order to model the choice not to purchase, we must make an assumption on the size of the potential market. In practice, the assumption on the potential market primarily affects the constant term, but not the other parameters.
} 
We denote $v_{i l}(b)$ as the indirect utility from holding bundle $b_{i}$ for opportunity $l$ :

$$
v_{i l}(b)=\max _{j \in b_{i}, c \in\{1, \ldots, C\}} u_{i j c l}
$$

At the time of adoption, the consumer is concerned with the expected indirect utility, averaged over $\varepsilon_{i j c l}^{u}$. One can think of this as the average over payment opportunities $l$ :

$$
v_{i}(b)=E\left[v_{i l}(b)\right]
$$

5 Now consider stage 1 , the adoption stage. The consumer knows $\delta_{i j c}$ and the distribution of $\varepsilon_{i j c l}^{u}$ but not the realizations. Thus, the consumer knows $v_{i}(b)$ for each possible bundle $b \in B$. The value to consumer $i$ of adopting bundle $b$ is:

$$
V_{i b}=\bar{V}_{i b}+\varepsilon_{i b}^{a}=\sum_{j \in b} \lambda_{i j}+v_{i}(b)+\varepsilon_{i b}^{a} .
$$

The parameters $\lambda_{i j}$ represent a payment instrument-specific utility term in excess of any utility from use. It could be an explicit cost such as an annual fee, or represent the cost of learning or paperwork. We refer $\lambda_{i j}$ as the adoption cost of $j$ to $i$, although $\lambda_{i j}$ is not restricted to be negative and could be an "adoption benefit." The variable $\varepsilon_{i b}^{a}$ represents utility that is idiosyncratic to the consumer and the bundle (the superscript "a" refers to adoption). The consumer picks $b$ such that $V_{i b} \geq V_{i b^{\prime}}$ $\forall b^{\prime} \in B$. Thus, consumers select a bundle of payment instruments in anticipation of their use preferences in the second period.

We do not observe variation in prices of usage and adoption, but we assume those to be captured in the usage value $\delta_{i j c}$ and the adoption cost $\lambda_{i j}$. Thus, a change in fees can be modeled as a change in one of these values. An increased usage fee lowers $\delta_{i j c}$ whereas an increase in an adoption fee raises $\lambda_{i j}$. Similarly, we model a reduction in a rewards program as a reduction in $\delta_{i j c}$. In practice, consumers may not treat pecuniary benefits and costs symmetrically. For instance, consumers may value a dollar surcharge to using a card asymmetrically to a dollar subsidy to using a card. We do not observe fees or subsidies, so this is not an issue for us in estimation. Rather, we look at how demographic variables predict adoption and usage, so we capture the extent to which demographic variables, such as education, affect how consumers make choices. In our counterfactual analysis, we adjust $\delta_{i j c}$ and $\lambda_{i j}$ directly, so it may be interpreted either as a reduction in rewards or an increase in an explicit cost. 
We do not model the fact that some payments "must be paid" (such as food purchases or bills). Whatever desire the consumer has to make a payment is captured by $\delta_{i j c}$, the consumer utility from allocating a payment opportunity to that context and instrument. This approach captures the issues we hope to address, namely substitution across contexts and instruments in response to demographics, preferences and the instrument portfolio.

Note that in our model, the adoption cost of a bundle of payment instruments is simply the sum of the adoption costs of the individual instruments. There are no "economies of scope" or other such causal effects of adoption of one instrument on the other payment instruments. Rather, we match joint adoption patterns by allowing for correlated preferences through the unobserved elements of $\lambda_{i j}$ (discussed below). It is difficult to separate causal and correlated effects, and we feel that our assumptions are reasonable. Of course, we allow for a negative causal effect of adoption of one payment instrument on the value of the others through use-for instance, adopting a credit card will make adopting a debit card less valuable since those instruments are substitutes in use. Our assumption is that adopting one has no effect on the adoption cost of the other.

\section{Estimation}

This section provides our parametric assumptions and our estimation strategy. In the second-stage problem (the use stage), we assume that $\varepsilon_{i j c l}^{u}$ is distributed Type 1 Extreme Value. We normalize the value of no payment to zero, so $\delta_{i 0}=0$. ${ }^{14}$ Therefore, the probability (or expected share) of payment instrument $j$ and context $c$ by consumer $i$ integrated across options $l$ is:

$$
s_{i j c}=\frac{\exp \left(\delta_{i j c}\right)}{\sum_{k \in b_{i}} \sum_{d \in C} \exp \left(\delta_{i k d}\right)} .
$$

The Extreme Value assumption implies that the distribution of the value of opportunity $l$ when holding bundle $b$ (from Equation 1) follows:

$$
v_{i l}(b)=\ln \left(\sum_{j \in b} \sum_{c \in C} \exp \left(\delta_{i j c}\right)\right)+\varepsilon_{i l}^{u},
$$

\footnotetext{
${ }^{14}$ Here, the subscripting of $\delta_{i 0}$ refers to the option $j=0$, which implies there is no context chosen.
} 
where $\varepsilon_{i l}^{u}$ is also distributed Type 1 Extreme Value. The mean of a variable with this distribution is Euler's constant, $\gamma$. Therefore, the expected value of bundle $b$, now averaging across the $L$ purchases is:

$$
v_{i}(b)=E\left[v_{i l}\left(b_{i}\right)\right]=\ln \left(\sum_{j \in b} \sum_{c \in C} \exp \left(\delta_{i j c}\right)\right)+\gamma
$$

In the first stage, we assume that $\varepsilon_{i b}^{a}$ is distributed Type 1 Extreme Value and is 5 iid across consumers and bundles. Therefore, the probability of picking bundle $b_{i}$ is:

$$
\operatorname{Pr}\left(b_{i}\right)=\frac{\exp \left(\bar{V}_{i b}\right)}{\sum_{k \in B} \exp \left(\bar{V}_{i k}\right)} .
$$

Although we assume that the consumer knows both $\delta_{i j c}$ and $\lambda_{i j}$, we allow the econometrician to face uncertainty about these values. We assume that:

$$
\delta_{i j c}=x_{i j c} \beta_{\delta}+\nu_{i j c}
$$

The vector $x_{i j c}$ is a set of observable characteristics about the individual, the payment choice and the context, and possibly some interactions between these. The variable $\nu_{i j c}$ represents the quality that consumer $i$ perceives for method $j$ in context $c$ that is unobserved to the researcher.

For the instruments besides cash and check, we assume that:

$$
\lambda_{i j}=z_{i j} \beta_{\lambda}+\omega_{i j}
$$

The vector $z_{i j}$ represents payment instrument-specific observable characteristics. Let the vector $\nu_{\mathbf{i}}$ be the $C \times J$ vector of terms $\nu_{i j c}$, which includes terms for products that are part of $b_{i}$ and for those that are not. ${ }^{15}$ Similarly, define $\omega_{\mathbf{i}}$ to be the $J-2$ vector of values of $\omega_{i j}$. The "-2" reflects the fact that we assume that consumers always adopt check and cash, so we do not model those adoption choices. We assume that the unobservable terms are distributed multivariate normal, possibly with correlation. Thus, $\left\{\nu_{\mathbf{i}}, \omega_{\mathbf{i}}\right\} \sim \mathbb{N}(0, \Sigma)$, with joint $\operatorname{CDF} \Phi$ and joint PDF $\phi$. The set of parameters

\footnotetext{
${ }^{15}$ In fact, not every instrument can be used in every context in our survey (as reflected in Table 3), and we restrict our consumers to be unable to make such a choice. Because of this issue, we will never observe the full set of $C \times J$ market shares. We ignore this issue in our notation for this section.
} 
to estimate is $\theta=\left\{\beta_{\delta}, \beta_{\lambda}, \Sigma\right\}$.

In order to construct the likelihood function, let $y_{i j c}^{*}$ be the observed number of transactions that $i$ allocates to instrument $j$ and context $c$, and $b_{i}^{*}$ be the observed bundle. That is, the "**" symbol indicates data. Let $\mathbf{y}_{\mathbf{i}}^{*}$ be the vector made up of 5 elements $y_{i j c}^{*}$. Then, the likelihood function is:

$$
\mathcal{L}_{i}\left(\mathbf{y}_{\mathbf{i}}^{*}, b_{i}^{*} \mid \theta\right)=\int_{\nu_{\mathbf{i}}} \int_{\omega_{i}} \operatorname{Pr}\left(\mathbf{y}_{\mathbf{i}}^{*}, b_{i}^{*} \mid \theta, \nu_{i}, \omega_{i}\right) f\left(\nu_{i}, \omega_{i}\right) d \omega_{i} d \nu_{i}
$$

That is, we integrate out the unobserved terms $\nu_{i}$ and $\omega_{i}$ to construct our likelihood function. Because this is an integral over a high-dimensional multivariate normal distribution, we turn to simulation techniques to compute our likelihood. In what follows, we present computational details of our algorithm for interested readers.

The elements of $\Sigma$ affect the substitution patterns, and the correlation between first and second-stage choices. We can potentially allow for arbitrary correlation among the elements of $\nu_{i j c}$ and $\omega_{i j}$ through the parameter matrix $\Sigma$. In practice, we restrict the elements of $\Sigma$ but allow it to have the flexibility to address several issues. In particular, we allow consumers to have correlated unobserved usage values for using an instrument in different contexts, as well as correlated unobserved usage values for different instruments in the same context. For example, a consumer may have an idiosyncratic preference to pay by credit card or to shop online. In addition, we allow for correlation between $\nu_{i j c}$ and $\omega_{j}$ when they refer to the same instrument. This feature introduces a selection effect, so that consumers who value an instrument for unobserved reasons also have different unobserved adoption costs for that instrument.

In particular, let $\varepsilon_{i j c}^{1}$ be distributed standard normal, independent across $i, j$, and $c$. Let $\varepsilon_{i j}^{2}$ be standard normal and independent across $i$ and $j$, but be constant across c. Let $\varepsilon_{i c}^{3}$ be defined analogously. Then we define:

$$
\begin{aligned}
\nu_{i j c} & =\sigma^{1} \varepsilon_{i j c}^{1}+\sigma_{j}^{2} \varepsilon_{i j}^{2}+\sigma_{c}^{3} \varepsilon_{i c}^{3} \\
\omega_{i j} & =\sigma_{j}^{4} \varepsilon_{i j}^{4}+\sigma_{j}^{5} \varepsilon_{i j}^{2} .
\end{aligned}
$$

Thus, $\sigma^{1}, \sigma_{j}^{2}$, and $\sigma_{c}^{3}$ determine the variance of use utility, with $\sigma_{j}^{2}$ measuring in25 strument correlation and $\sigma_{c}^{3}$ measuring context correlation. For adoption, $\sigma_{j}^{4}$ and $\sigma_{j}^{5}$ determine the variance. Together, $\sigma_{j}^{2}$ and $\sigma_{j}^{5}$ determine the correlation between unobserved adoption and use. That is, they determine the selection effect. Note that 
the selection effect could be negative if $\sigma_{j}^{2}$ and $\sigma_{j}^{5}$ have opposite signs.

It is straightforward to add further shocks. We experiment with several extensions. Since we are particularly motivated by public policy towards debit cards, we are interested in allowing rich substitution patterns for debit cards. Debit cards are close to credit because they are both card based, and close to cash since payment is immediate. Check is also an important potential substitute. Therefore, the results that we present below come from a specification in which we have added three further shocks. Each shock enters the use value of two instruments, debit-cash, debit-check and debit-credit. We add 6 parameters to the model to govern the effect of each shock in each instrument. Thus, we allow for further (possibly negative) correlation between these three pairs of payment instruments.

Our algorithm proceeds by first generating $n s$ draws of the vector of values $\left\{\bar{\varepsilon}^{1}, \bar{\varepsilon}^{2}, \bar{\varepsilon}^{3}, \bar{\varepsilon}^{4}\right\}$ (in practice, from a Halton sequence as opposed to a pseudo-random number generator), where $n s$ is the number of draws we use in our simulation estimator. Based on the current guess of parameters in $\Sigma$, we use these draws to construct values of $\nu_{i j c}^{s}$ and $\omega_{i j}^{s}$ according to Equation 6, where superscript $s$ refers to the simulation draw, $s=1, \ldots, n s$. We use the values of $\nu_{i j c}^{s}$ and $\omega_{i j}^{s}$ to construct $\delta_{i j c}^{s}$ using Equation 4 and values of $\lambda_{i j}^{s}$ using Equation 5. Based on $\delta_{i j c}^{s}$, we construct $v_{i}^{s}(b)$ from Equation 3 (the values from use of each bundle, consumer, and draw). With $v_{i b}^{s}$ and $\lambda_{i j}^{s}$, we construct $\bar{V}_{i b}^{s}$ from Equation 2 (the value of adoption). Using $\delta_{i j c}^{s}$ and $\bar{V}_{i b}^{s}$ we can construct our simulated likelihood function:

$$
\widehat{\mathcal{L}}_{i}\left(\mathbf{y}_{\mathbf{i}}^{*}, b_{i}^{*} ; \theta\right)=\frac{1}{n s} \sum_{s=1}^{n s} \operatorname{Pr}\left(\mathbf{y}_{\mathbf{i}}^{*} \mid b_{i}^{*}, \nu_{i}^{s}, \omega_{i}^{s}, \theta\right) \operatorname{Pr}\left(b_{i}^{*} \mid \nu_{i}^{s}, \omega_{i}^{s}, \theta\right)
$$

where:

$$
\begin{aligned}
\operatorname{Pr}\left(\mathbf{y}_{\mathbf{i}}^{*} \mid b_{i}^{*}, \nu_{i}^{s}, \omega_{i}^{s}, \theta\right) & =\prod_{j \in b_{i}^{*}} \prod_{c \in C}\left(\frac{\exp \left(\delta_{i j c}^{s}\right)}{\sum_{k \in b_{i}^{*}} \sum_{d \in C} \exp \left(\delta_{i k d}^{s}\right)}\right)^{y_{i j c}^{*}} \\
\operatorname{Pr}\left(b_{i}^{*} \mid \nu_{i}^{s}, \omega_{i}^{s}, \theta\right) & =\frac{\exp \left(\bar{V}_{i b^{*}}^{s}\right)}{\sum_{k \in B} \exp \left(\bar{V}_{i k}^{s}\right)} .
\end{aligned}
$$

As in any approach that relies on maximum simulated likelihood, bias is introduced since $\mathcal{L}_{i}$ is approximated with simulation error, which enters nonlinearly (since we actually maximize the logarithm of the simulated likelihood) into our objective 
function. See Pakes and Pollard (1989) and Gourieroux and Montfort (1996). Maximum simulated likelihood is consistent only as $n s$ goes to $\infty$. Fortunately, our objective function is not difficult to compute, and so we set $n s$ high, equal to 200 in what we present below, such that we expect this problem is minimized. Raising this value does not importantly impact our results.

Several issues deserve discussion. In reality, adoption is dynamic, whereas we model it as being static. In practice, a consumer may adopt an instrument, experiment with it and learn different ways in which it might be used, and perhaps build up a comfort level with it that affects her propensity to substitute to newer technologies, such as debit or prepaid cards. We ignore these issues - one would need a panel in order to study dynamic adoption and particularly one would need detailed use data to study learning - but we regard this issue as interesting and potentially important.

A second issue is that we rely heavily on consumer ratings of payment instruments. These ratings are self-reported evaluations and therefore reporting may vary across consumers, and there may be bias in how the ratings are determined - for instance, consumers may assign high ratings to their own choices ex post that they would not have assigned ex ante. However, we found the results of the ratings consistent with our expectations, in both the simple statistics and the estimation results. Schuh and Stavins (2010; 2013) also find them to be important.

Lastly, we discuss standard errors. We compute standard errors using the outer product of the gradient to compute the information matrix. We adjust the inverse of information matrix upwards to account for simulation error, as in Pakes and Pollard (1989). In practice, we follow the discussion in Train (2003) on addressing the issue of simulation. The consumer-level shocks at the level of the context and instrument (the latter which affects both adoption and usage) can be interpreted as a form of clustering in the sense of Moulton (1990), who advocates for consumer-level shocks to address standard errors in a panel data context. The estimates of our use parameters are more precise than our adoption parameters because we observe each consumer make many use choices but only one adoption choice (although in computing standard errors, we always treat the number of observations as the number of consumers, not the number of consumers times the number of use choices). 


\section{Model Comparison and Identification}

Our model fits into a general literature in which agents first make a discrete choice about adoption and then adopters make an ordered or continuous choice over intensity of use. In this section, we highlight the contribution of our model to the existing literature. Important early citations are Dubin and McFadden (1984) and Hanemann (1984). More recently, Hendel (1999), Burda, Harding, and Hausman (2012) and Dube (2004) also fit in this area. There is also a similarity to the Heckman (1979) selection model, in which an initial discrete choice determines whether we observe a continuous outcome variable. As a general example of a Heckman model, consider a discrete choice $Y \in\{0,1\}$, where we observe $w$ if $Y=1 .{ }^{16}$ A standard approach would be to model a latent variable $Y^{*}$ where $Y=1$ if $Y^{*}>0$ and $Y=0$ otherwise, with:

$$
\begin{aligned}
Y^{*} & =z \beta_{z}+\varepsilon_{y} \\
w & =x \beta_{x}+\varepsilon_{w} .
\end{aligned}
$$

The standard approach to estimate the Heckman selection model is to estimate the discrete choice model in a first step and then address correlation between $\varepsilon_{y}$ and ${ }_{15} \varepsilon_{w}$ with a control function approach that includes a function of the first-stage results in the linear second stage. This is also the approach followed by Dubin and McFadden (1984) in the context of electricity use and the adoption of electric appliances. However, note that in this approach, $w$ is not allowed to influence the discrete choice directly. We typically assume that $x \in z$, and we could further assume that $\varepsilon_{y}=\varepsilon_{w}+u_{y}$, that is, that $\varepsilon_{y}$ equals $\varepsilon_{w}$ plus some further noise. Then, the agent observes all of the elements of $w$ when making the discrete decision, and so has perfect foresight. However, the effect of $w$ on $Y$ is captured in reduced form. The weakness of this approach from our perspective is it does not identify the causal effect of $w$ on $Y$.

In contrast, our model allows for the structural identification of the effect of use on adoption. Furthermore, like the Heckman model, our model allows for the consumer in the adoption stage to predict usage better than the econometrician. The former is attractive since we are specifically interested in distinguishing the effect of changes

\footnotetext{
${ }^{16}$ Note that the notation in this section is meant to convey the Heckman model, and is unrelated to the structural model we develop for this paper.
} 
in adoption costs from the effect of changes in use values. The latter is attractive because it is a realistic and flexible approach. ${ }^{17}$

Although the Heckman selection model is often estimated as a two-step model, our model with use directly affecting adoption is akin to a simultaneous equations model.

${ }_{5}$ This leads us to another point: Whereas identification in the Heckman selection model requires an excluded variable in the first equation, our simultaneous equations approach requires excluded variables in both equations. We use consumer ratings of categories that should be relevant only for adoption or only for use, such as ratings of set-up cost and the ease of use.

In addition to the identification issues associated with the discrete-continuous element of the model, we also face identification issues associated with bundled choice. Importantly, we model the value of a bundle as being additively separable in adoption costs. That is, adopting one payment method does not raise or lower the costs of adopting another payment method. An important issue in estimating the demand for bundles of goods is how one distinguishes between the causal effect that adopting one element of a bundle has on the value of adopting other elements, and correlation in the utility of elements. If we observe a positive correlation in the adoption of two instruments, we cannot tell whether the instruments are truly complements or whether consumers who like one instrument also tend to like the other. The distinction is important: an exogenous change in the price of one payment instrument affects the use of the other payments in different ways depending on these assumptions.

We address this identification issue by assuming that payment methods are substitutes through use only. That is, adopting a debit card does not make it harder or easier to adopt a credit card. However, a person who adopts a debit card may be less likely to adopt a credit card because he expects to use a credit card less often. Our model still accommodates high joint adoption of credit and debit cards by allowing people who have low adoption costs for debit to also have low adoption costs for credit. Thus, we expect the logit use model to capture the extent to which payment methods, such as debit and credit, are substitutes. Correlation will be captured

\footnotetext{
${ }^{17}$ This feature distinguishes our model from several models that model discrete and multiple choices, such as Burda, Harding, and Hausman (2012). We are not aware of a similar discussion to ours of the role of consumer information and structural modeling in the discrete-continuous demand literature. However, our model is not the first structural model to have the feature that the decisionmaker predicts the second stage of a two-stage model better than the econometrician. Some examples appear in structural labor and environmental economics.
} 
in the covariance matrix governing unobserved elements of use utility and adoption cost. Other papers have similarly employed use to identify substitution in an adoption context, such as Ryan and Tucker (2012) and Crawford and Yurukoglu (2012). This approach differs from Gentzkow (2007), who uses an instrumenting strategy to

5 separate these issues. Note that our model rules out the possibility that payment methods are complements. ${ }^{18}$ We believe this is realistic and consistent with our data.

\section{Results}

In addition to the "full model" described above (the model of both usage and adoption), we also provide estimates of a "use-only" model, which is the use stage alone, ignoring the adoption stage. In the use-only model, we estimate the part of the model that predicts the number of transactions for each context-instrument taking the portfolio of instruments as given, and we do not include the part of the model that predicts the portfolio of instruments. These results provide a useful comparison because they do not address the selection inherent in the adoption decision. The results of the use-only model tend to be closer to the raw data, and comparing them to the full model highlights when we can rely on raw data and when we cannot.

For explanatory variables in the use equation (the elements of $x$ ), we include context-instrument fixed effects, consumer ratings (except for the rating of set-up cost) of the payment instrument, demographics (age, income, gender, marital status, employment status, and education level) separately for cash, check, debit and credit. We do not include demographics for the other instruments in order to preserve degrees of freedom. For explanatory variables in the adoption equation (the elements of $\mathrm{z}$ ), we include payment instrument dummies and demographics (income, education and employment status), as well as the consumer rating of the set-up experience. ${ }^{19}$

Table 6 provides the average utility of each payment instrument-context combination in the use equation. Table 6 presents the average across all consumers, whether they hold the instrument or not. For essential retail, cash and debit are the most

\footnotetext{
${ }^{18}$ Our approach would be more problematic if we were also modeling the adoption of bank accounts. Naturally, adopting a bank account makes it easier to adopt a credit card (since consumers typically pay a credit card bill out of a bank account), a debit card, on-line bill-pay, and others. However, we study only consumers that hold bank accounts.

${ }^{19}$ We also experimented with a sample that was restricted to consumers who do not carry a balance. Results were similar, both for parameters and counterfactual experiments.
} 
popular instruments, followed by credit cards. Check is further back, with prepaid cards being the least popular. The dominance of cash and debit card in this context can also be seen from Table 3, which presents the average number of transactions per instrument and context. For nonessential retail, debit and cash are still dominant, may reflect the fact that credit cards enable non-essential purchases via their credit function, and enable consumers to smooth payments for larger purchases. Notably, this latter result is not directly observed from the raw data: in Table 3, credit card still lags behind cash in terms of transaction counts. This is because the average transaction count by credit card depends not only on the average utility of that instrument, but also on a host of other factors, such as the rates of adoption of credit card, the socio-demographic composition of credit card users, and so on. The structural model accounts for all of these extra factors and delivers the base utility of each instrument in each context. For online retail, the results are very similar for all 15 payment instruments except for prepaid cards, which are more seldom used to make purchases on the Internet. In fact, the only context where the prepaid card has any meaningful utility is essential retail: even though the average transaction count is just 0.1 and the average for checks is much higher at 1 transaction per typical month (Table 3), our model finds that prepaid is almost as valuable as checks. This gap between the models prediction and raw data is explained by the sparse adoption of prepaid cards (see Table 1), in contrast to universal adoption of checks.

In the bill-pay contexts, checks are much preferred to cash, debit, or credit, provided that checks are accepted (Mail/In person bill-pay). In the area of electronic billpay, such methods as online banking and automatic deductions are popular. These 25 patterns follow the data averages found in Table 3.

Table 7 presents the effect of each demographic variable on each payment instrument in the use equation. The coefficients represent the extra preference (positive or negative) that a particular demographic group places on a particular payment instrument. In interpreting this table, keep in mind that the parameters are relative to the outside option of not making a transaction. So for instance, consider the variable age. If all the coefficients were positive and of the same size, that would tell us that older consumers make more transactions, but that they prefer all instruments with the same relative proportions as younger consumers. That is, a positive coefficient on age for one instrument does not mean that older consumers use that instrument 


\begin{tabular}{|c|c|c|c|c|c|c|c|}
\hline & \multicolumn{3}{|c|}{ Bill Pay } & \multicolumn{3}{|c|}{ Retail } & \multirow[b]{2}{*}{ Other } \\
\hline & Automatic & Online & In person & Online & Essential & Non-essential & \\
\hline \multirow[t]{2}{*}{$\overline{C a s h}$} & & & -6.87 & & -4.45 & -5.55 & -4.89 \\
\hline & & & $(0.11)$ & & $(0.11)$ & $(0.11)$ & $(0.11)$ \\
\hline \multirow[t]{2}{*}{ Check } & & & -4.81 & -6.04 & -6.27 & -6.86 & -5.20 \\
\hline & & & $(0.12)$ & $(0.12)$ & $(0.12)$ & $(0.13)$ & $(0.12)$ \\
\hline \multirow[t]{2}{*}{ Debit card } & -6.10 & -6.25 & -6.48 & -5.82 & -4.31 & -5.27 & -4.99 \\
\hline & $(0.13)$ & $(0.12)$ & $(0.13)$ & $(0.12)$ & $(0.12)$ & $(0.12)$ & $(0.12)$ \\
\hline \multirow[t]{2}{*}{ Credit card } & -6.45 & -6.74 & -6.68 & -6.01 & -4.82 & -5.54 & -5.17 \\
\hline & $(0.13)$ & $(0.13)$ & $(0.13)$ & $(0.13)$ & $(0.13)$ & $(0.13)$ & $(0.13)$ \\
\hline \multirow[t]{2}{*}{ Prepaid card } & & & -8.66 & -8.07 & -6.74 & -7.69 & -7.60 \\
\hline & & & $(0.49)$ & $(0.40)$ & $(0.41)$ & $(0.47)$ & $(0.46)$ \\
\hline Online banking & & $\begin{array}{l}-4.95 \\
(0.08)\end{array}$ & & & & & \\
\hline \multirow[t]{2}{*}{ Bank acct. deduct } & -5.14 & -5.51 & & -5.82 & & & \\
\hline & $(0.09)$ & $(0.09)$ & & $(0.09)$ & & & \\
\hline \multirow[t]{2}{*}{ Income deduction } & -5.06 & & & & & & \\
\hline & $(0.07)$ & & & & & & \\
\hline
\end{tabular}

Notes: Standard errors are in parenthesis. 997 observations, unweighted.

Table 6: Average Utilities by Context and Payment Instrument in Use Equation.

more than other instruments. The size of the coefficient must be compared to the coefficient on age for other instruments.

In fact, from the "Full model" column, we find that the coefficient on check is higher than the coefficients on cash, credit and debit, and all of them are positive.

5 Together, these results tell us that older consumers make more transactions, and that they place more preference on checks than do younger consumers. This result is not surprising and is similar to previous research. The surprise is that age coefficients on cash, credit and debit are of similar magnitude, indicating that older consumers do not place a higher preference on cash relative to credit and debit. It is notable that we find this result only in our full model, that is, when we account for the fact that older consumers hold relatively more payment instruments. The use-only model, which takes the adoption decisions as given, predicts that debit card use declines with age, just as in Borzekowski, Kiser, and Ahmed (2008). This difference in results between the full and the use-only models emphasizes the observed frequencies of use of payment instruments is a noisy indicator of preferences, due to its dependence on the bundle of available choices.

Analyzing the results, we find that wealthier consumers prefer credit cards. The "Use-only" column indicates that less wealthy consumers use cash more than wealthy consumers, similar to the literature (see, for example Wang and Wolman 2014). 


\begin{tabular}{crlrr} 
& Use only model & \multicolumn{2}{c}{ Full model } \\
\hline Household income & \multicolumn{5}{c}{} \\
\hline Intercept & 0.04 & $(0.003)$ & 0.002 & $(0.003)$ \\
Cash & -0.07 & $(0.004)$ & 0.001 & $(0.004)$ \\
Check & 0.01 & $(0.004)$ & -0.01 & $(0.006)$ \\
Debit & 0.02 & $(0.005)$ & 0.02 & $(0.006)$ \\
Credit & 0.04 & $(0.006)$ & 0.05 & $(0.006)$ \\
Prepaid & -0.25 & $(0.076)$ & -0.11 & $(0.026)$
\end{tabular}

Education: college degree or higher

\begin{tabular}{|c|c|c|c|c|c|}
\hline & Intercept & 0.14 & $(0.02)$ & 0.22 & $(0.02)$ \\
\hline & Cash & -0.05 & $(0.02)$ & -0.16 & $(0.03)$ \\
\hline & Check & -0.18 & $(0.02)$ & -0.21 & $(0.03)$ \\
\hline & Debit & -0.96 & $(0.02)$ & -0.58 & $(0.02)$ \\
\hline & Credit & 0.46 & $(0.03)$ & 0.51 & $(0.03)$ \\
\hline & Prepaid & 0.21 & $(0.29)$ & 0.06 & $(0.17)$ \\
\hline \multicolumn{6}{|l|}{ Age } \\
\hline & Intercept & -0.005 & $(0.01)$ & -0.02 & $(0.01)$ \\
\hline & Cash & -0.02 & $(0.01)$ & 0.08 & $(0.01)$ \\
\hline & Check & 0.13 & $(0.01)$ & 0.25 & $(0.01)$ \\
\hline & Debit & -0.06 & $(0.01)$ & 0.07 & $(0.01)$ \\
\hline & Credit & -0.02 & $(0.01)$ & 0.08 & $(0.01)$ \\
\hline & Prepaid & 0.29 & $(0.09)$ & -0.10 & $(0.04)$ \\
\hline \multicolumn{6}{|l|}{ Male } \\
\hline & Intercept & 0.02 & $(0.02)$ & -0.05 & $(0.02)$ \\
\hline & Cash & -0.10 & $(0.02)$ & 0.20 & $(0.03)$ \\
\hline & Check & -0.17 & $(0.02)$ & -0.36 & $(0.03)$ \\
\hline & Debit & -0.22 & $(0.02)$ & -0.12 & $(0.03)$ \\
\hline & Credit & 0.08 & $(0.03)$ & -0.01 & $(0.03)$ \\
\hline & Prepaid & -3.32 & $(0.40)$ & -0.29 & $(0.18)$ \\
\hline \multicolumn{6}{|c|}{ Married } \\
\hline & Intercept & 0.05 & $(0.02)$ & 0.19 & $(0.02)$ \\
\hline & Cash & 0.04 & $(0.03)$ & -0.18 & $(0.03)$ \\
\hline & Check & 0.11 & $(0.03)$ & 0.19 & $(0.03)$ \\
\hline & Debit & -0.59 & $(0.03)$ & -0.59 & $(0.03)$ \\
\hline & Credit & 0.33 & $(0.03)$ & 0.06 & $(0.03)$ \\
\hline & Prepaid & 1.01 & $(0.37)$ & -0.60 & $(0.16)$ \\
\hline \multicolumn{6}{|c|}{ Employed } \\
\hline & Intercept & 0.08 & $(0.02)$ & 0.19 & $(0.02)$ \\
\hline & Cash & 0.06 & $(0.03)$ & -0.03 & $(0.03)$ \\
\hline & Check & -0.25 & $(0.03)$ & -0.13 & $(0.03)$ \\
\hline & Debit & 0.48 & $(0.03)$ & 0.28 & $(0.03)$ \\
\hline & Credit & -0.35 & $(0.03)$ & -0.29 & $(0.03)$ \\
\hline & Prepaid & -1.96 & $(0.25)$ & -0.26 & $(0.15)$ \\
\hline
\end{tabular}

Notes: 997 observations, unweighted. Standard errors are in parenthesis. The Use only model does not include the adoption stage.

Table 7: Partial effect of socio-economic status on value of usage. 
However, the "Full" column indicates that this effect is due in part to selection. In the full model, the coefficient of income on cash use is higher, being close to zero and insignificant. Still, the coefficient on income for cash is lower than for other instruments, telling us that the share of cash use declines with income. Similarly, effect is substantially reduced when accounting for selection.

Education has a large positive effect on credit card use, and a significant negative effect on cash, check and debit. The positive relationship of education with credit use and the negative one with debit use are largely supported by the existing studies. 10 Using scanner data, Klee (2008) finds that education is positively associated with the use of credit cards and negatively with cash and checks. Borzekowski and Kiser (2008) report that survey respondents with a bachelor or graduate degree show disutility from spending from liquidity, meaning a debit card. One limitation of the existing results is that the literature typically does not emphasize separate effects of education on 15 usage and on adoption. Using our two-stage model, we find that with respect to credit, education is associated with both lower adoption costs and higher utility of usage (see Table 7 for usage and Table 10, discussed below, for adoption results). A similar result, but with the opposite sign, holds for debit.

The effects we find here could result from an inherent preference by high income, or high education consumers for credit over debit use, but presumably also reflect that these groups are likely to have higher reward cards, have higher limits, higher lifetime income, and are better at managing balances and fees.

Even though we find that higher income consumers prefer credit cards, the relationship between employment and credit card use is the opposite: employed consumers use credit cards less than unemployed ones. This finding comes through both in the raw data and in the estimation. Perhaps these results reflect the conflicting roles that credit cards play in household finance; whereas income and employment makes credit cards more attractive and easier to manage, they also make the credit feature less necessary. We also find that males prefer cash and particularly credit card relative to debit or check.

Next in Table 8, we consider the role of consumer ratings. Similar ratings variables were consistently found to be important in other studies that rely on surveys, such as Schuh and Stavins (2010),Borzekowski and Kiser (2008), Arango, Huynh, and Sabetti (2015), Klee (2008) and Ching and Hayashi (2010).Overall, our results find 


\begin{tabular}{lrrrr}
\hline & Use only model & \multicolumn{2}{c}{ Full model } \\
\hline Security & -0.01 & $(0.003)$ & 0.04 & $(0.003)$ \\
Acceptance & 0.01 & $(0.005)$ & 0.02 & $(0.005)$ \\
Cost of use & 0.10 & $(0.004)$ & 0.08 & $(0.005)$ \\
Control of pay time & 0.03 & $(0.004)$ & $0.08(0.004)$ \\
Record keeping & 0.08 & $(0.005)$ & 0.002 & $(0.005)$ \\
Speed & 0.01 & $(0.005)$ & 0.04 & $(0.005)$ \\
Ease of use & 0.12 & $(0.006)$ & 0.10 & $(0.006)$ \\
\hline
\end{tabular}

Notes: 997 observations, unweighted. Standard errors are in parenthesis. The "use" model does not include the adoption stage.

Table 8: Effect of Payment Characteristics on Use.

that consumer ratings are important predictors of payment choice, as they explain about the same amount of variation in use as the demographic variables, although they account for far fewer parameters. ${ }^{20}$ All of the ratings variables have a positive effect on payment use, as expected. Ease of use is the most important determinant of use, followed by control and cost of use. Perhaps surprisingly, we find that although the coefficient on security is positive and statistically significant, it is smaller than for a number of the other ratings. This result appears in other settings as well. For instance, Arango, Huynh, and Sabetti (2015) find that security has an insignificant, and even a slightly negative effect on the propensity to use credit cards. Ching and Hayashi (2010) also find safety to be insignificant in some specifications. We do not interpret these results as implying that security of a payment instrument is not important. It is possible that the security is important for new payment products, but is less important for relatively established payment instruments such as those in our study (see Rysman 2010).

Now we turn to results from the adoption equation. Table 9 shows the average adoption costs (which are not restricted to be positive, as discussed previously), by instrument. Higher values imply that an instrument is more costly to adopt. Since all consumers hold cash and check, we do not estimate costs for these variables. We see that credit cards and debit cards are the least costly to adopt. Prepaid cards are more costly than other card options, and indeed, prepaid cards have high fees in most cases. Interestingly, bank account deduction (which is often facilitated by employers

\footnotetext{
${ }^{20} \mathrm{We}$ compute this statistic by calculating the variance generated by demographic variables and payment characteristics in the prediction of mean utilities. Schuh and Stavins (2010) find a similar result.
} 


\begin{tabular}{lrr}
\hline & Coef. & Std. Err. \\
\hline Debit card & -1.42 & $(0.61)$ \\
Credit Card & -1.77 & $(0.70)$ \\
Online banking bill pay & 0.05 & $(0.31)$ \\
Prepaid & 1.49 & $(0.82)$ \\
Bank account deduction & -1.08 & $(0.31)$ \\
Income deduction & 1.61 & $(0.26)$ \\
\hline
\end{tabular}

Notes: 997 observations, weighted by population. Standard errors are in parenthesis.

Table 9: Mean values of adoption by instrument.

and mortgage companies) is regarded as very cheap to adopt, although not quite as inexpensive as credit or debit cards. Online bill-pay, which tends to require more initiative on the part of consumers, is more costly.

We include several additional covariates in the adoption decision: setup cost, 5 household income, education and employment status. The results are presented in Table 10. Again, a negative coefficient indicates lower adoption cost and vice versa. We find that a higher rating of set-up cost (which means the consumer believes set-up costs are low) leads to lower adoption cost of that instrument, as expected. Overall, adoption costs vary with income and payment instrument. Notice that the adoption cost of all of the instruments (except for prepaid cards) drops with income, but that the adoption cost of credit drops at the highest rate. The inverse relationship between adoption rates and income is also found in Hayashi and Klee (2003) in two separate surveys (see Table 3 in their study). With respect to education, Hayashi and Klee (2003) find a generally positive association with the adoption of debit, although the relationship is statistically insignificant in most specifications.

With respect to credit cards, the negative correlation between adoption cost and income may reflect both consumer preferences and the willingness of card companies to grant the credit line. We cannot separate the effect of income through these two channels, particularly because we do not observe application behavior. We think of our specification as a reduced form for the more complicated simultaneous equations model of consumer and bank decision-making. Therefore, to interpret our counterfactual changes in the usage value and adoption cost of debit cards, we must maintain 


\begin{tabular}{|c|c|c|}
\hline & Coef. & Std. err. \\
\hline \multicolumn{3}{|l|}{ Household income } \\
\hline Intercept & -0.06 & $(0.01)$ \\
\hline Debit & -0.01 & $(0.04)$ \\
\hline Credit & -0.17 & $(0.05)$ \\
\hline Prepaid & 0.03 & $(0.05)$ \\
\hline \multicolumn{3}{|c|}{ Education: college degree or higher } \\
\hline Intercept & -0.22 & $(0.09)$ \\
\hline Debit & 0.25 & $(0.25)$ \\
\hline Credit & -0.98 & $(0.32)$ \\
\hline Prepaid & 0.05 & $(0.24)$ \\
\hline \multicolumn{3}{|l|}{ Employed } \\
\hline Intercept & -0.08 & $(0.10)$ \\
\hline Debit & -0.34 & $(0.25)$ \\
\hline Credit & 0.48 & $(0.31)$ \\
\hline Prepaid & -0.27 & $(0.24)$ \\
\hline
\end{tabular}

Notes: 997 observations, unweighted. Standard errors are in parenthesis.

Table 10: Effect of Personal Characteristics on the Cost of Payment-Instrument Adoption. 
an assumption that the reduced-form relationship between income (and other explanatory variables) and credit card adoption remains constant. We believe this is a reasonable assumption.

The correlation matrix $\Sigma$ contains 19 parameters and generates a rich set of correlations. We defer a complete discussion to the Appendix. Overall, we find substantial correlation in unobserved usage utility across instruments and contexts, and we find a strong correlation between adoption and usage unobserved terms, generating an important selection effect into usage.

We find that the level of fit of the model is good, with an $R^{2}$ statistic of $50.5 \%$ when looking at the predictions of "market shares" of payment instrument, by context, in the usage stage. With 13,356 non-zero market share observations and only 102 parameters related to the usage equation, there is little danger of over-fitting. On a set of 100 randomly selected sub-samples, the distribution $R^{2}$ statistics has a median of $50.4 \%$ and a standard deviation of $2.04 \%$.

It is worthwhile to contrast our results with the findings of Schuh and Stavins (2013) who use the same survey data as we do but take a reduced-form approach to explaining adoption and use. Specifically, they estimate a separate Heckman equation for each of the seven payment instruments. ${ }^{21}$ Because the same data is used in both studies, the difference in results will mostly reflect the impact of restrictions imposed by the modeling approach. The most notable of these differences are that Schuh and Stavins (2013) do not allow for a structural effect of use on adoption, and they treat each instrument separately, rather than allowing for correlation or substitution in use and adoption. For the sake of brevity, we restrict our discussion to instruments that are actively adopted, e.g. other than cash and checks.

Overall, the results are similar, which we take as support for the general modeling approach. There are some interesting differences. Contrary to our results, Schuh and Stavins (2013) do not find a significant effect of income either on usage or on the adoption of credit and debit cards (except for households with under $\$ 25,000$ yearly income, which are much less likely to adopt both cards but represent only $11 \%$ of the population). In particular, our results suggest that higher income consumers have lower costs of adoption of a credit card. A possible explanation is that in order to

\footnotetext{
${ }^{21}$ The approach of Heckman (1979) is mathematically similar to the treatment of intensive and extensive margins in Dubin and McFadden (1984), except that the latter use a multinomial first stage.
} 
see that high income households use plastic more, the researcher must condition on the fact that high income households also hold many instruments. Also, we find the size of the selection effect (that is, the correlation between the unobserved elements of adoption and usage) are substantially larger than Schuh and Stavins (2013). ${ }^{22}$

\section{${ }_{5} 8$ Counterfactual experiments}

We first discuss counterfactual experiments that focus on debit cards, and then turn to credit cards. Our goal is to evaluate outcomes if consumers face per-use fees or adoption fees on card products.

\subsection{Debit cards}

In order to simulate a bank imposing a per-use fee (or eliminating a rewards program) on a debit card, we use our model at the estimated parameters to assess the consumer response to a reduction in the usage value of a debit card. In order to consider the effect of a bank imposing a fixed fee, such as a monthly fee on debit cards, we simulate the effect of an increase in the adoption cost. In addition to our policy motivation, these experiments provide magnitudes, in the sense of cross-elasticities, to the parameters in the previous sub-section.

Formally, let $\vec{\delta}$ be the $J \times C$ vector of average usage values. That is, element $j c$ is the average of $\delta_{i j c}$, averaged over $i$. Analagously, let $\vec{\lambda}$ be the $J-2$ vector of average adoption costs. Let $s^{d}(\vec{\delta}, \vec{\lambda})$ be the overall usage share of debit cards (a scalar value) among payment instruments (not including the outside option). For instance, at the estimated values $\vec{\delta}$ and $\vec{\lambda}$, we have that $s^{d}(\vec{\delta}, \vec{\lambda})=0.31$, the observed market share of transactions in the data (see Table 3 ). Let $\vec{\Delta}$ be a $J \times C$ vector of elements $\Delta_{j c}$, where $\Delta_{j c}$ takes on only two values, $\Delta$ or 0 . That is, $\Delta_{j c}=\Delta$ if $j$ refers to a debit card, and $\Delta_{j c}=0$ otherwise. Thus, we adjust all of the values of $\delta_{i j c}$ for debit cards. We find $\Delta$ such that $s^{d}(\vec{\delta}, \vec{\lambda})-s^{d}(\vec{\delta}-\vec{\Delta}, \vec{\lambda})=0.01 .^{23}$ Our focus is on how the

\footnotetext{
${ }^{22}$ One difference with the existing literature is that with respect to employment, our results imply that employed individuals derive lower benefit from credit cards both in the usage and in the adoption stage, while Schuh and Stavins (2013) conclude that employment is associated with a higher rate of credit card adoption, but does not bring an extra benefit from credit at the usage stage. Note that the effect of employment is subtle, and operates through income as well.

${ }^{23}$ Given our linear utility functions, reducing $\delta_{i j c}$ is equivalent to lowering a rating such as ease of use by the the same amount, scaled by the coefficient on the rating. In this interpretation, our
} 
market shares of other payment instruments respond to this change. We can similarly consider adjustments to $\vec{\lambda}$ that reduce debit market shares among transactions by 0.01. In this case, $\vec{\Delta}$ is $J-2 \times 1$ and has only one non-zero element. We choose 0.01 because we want a small value, to approximate an elasticity.

We also distinguish between the responses of consumers holding payment instrument adoption fixed (the "short run"), and allowing adoption to change (the "long run"). Changing adoption costs has no effect in the short-run, so we provide results for this experiment for the long-run only.

Figure 1 plots the estimated changes in the transactions market shares in usage of payment instruments other than debit cards in response to the reduction in the usage value of debit cards. To compute these results, we compute choices for each consumer in our data set and use the survey weights to construct a nationally representative result. We assume consumers cannot switch to the outside option (the option of not making a payment), which allows us to focus on substitution issues. ${ }^{24}$ For each counterfactual simulation, the decline in debit market share (not plotted in the figure) is one percentage point, so the increases in other market shares sum to one. Thus, one can view the market share changes as analogous to cross-price elasticities of demand for the use of other payment instruments. Figure 1 also graphs the 95\% confidence interval for the first experiment, calculated from the variance of the underlying parameters via the delta method. The confidence intervals for the other experiments look similar. We do not include them in order to make the figure less cluttered.

The three experiments predict that cash will pick up between 32 and $34 \%$ of debit's loss, with checks gaining about $25 \%$ and credit cards gaining $21 \%$. Thus, our model predicts that paper products (cash and check) dominate as substitutes to debit. Our model predicts only small differences across the three experiments. There is slightly higher substitution towards cash in response to the change in usage value than in response to the change in adoption cost. This result occurs because it is primarily wealthy people who stop using debit in response to adoption costs, and they have more options in their portfolio than low income consumers, and are more likely to experiment could potentially lower some ratings below zero. However, we do not regard this issue as particularly problematic.

${ }^{24}$ We do not study substitution to the outside option since the results will depend highly on how we set the potential market $(L)$, which is somewhat arbitrary. However, our results for substitution between payment instruments should be robust to different values of $L$. 


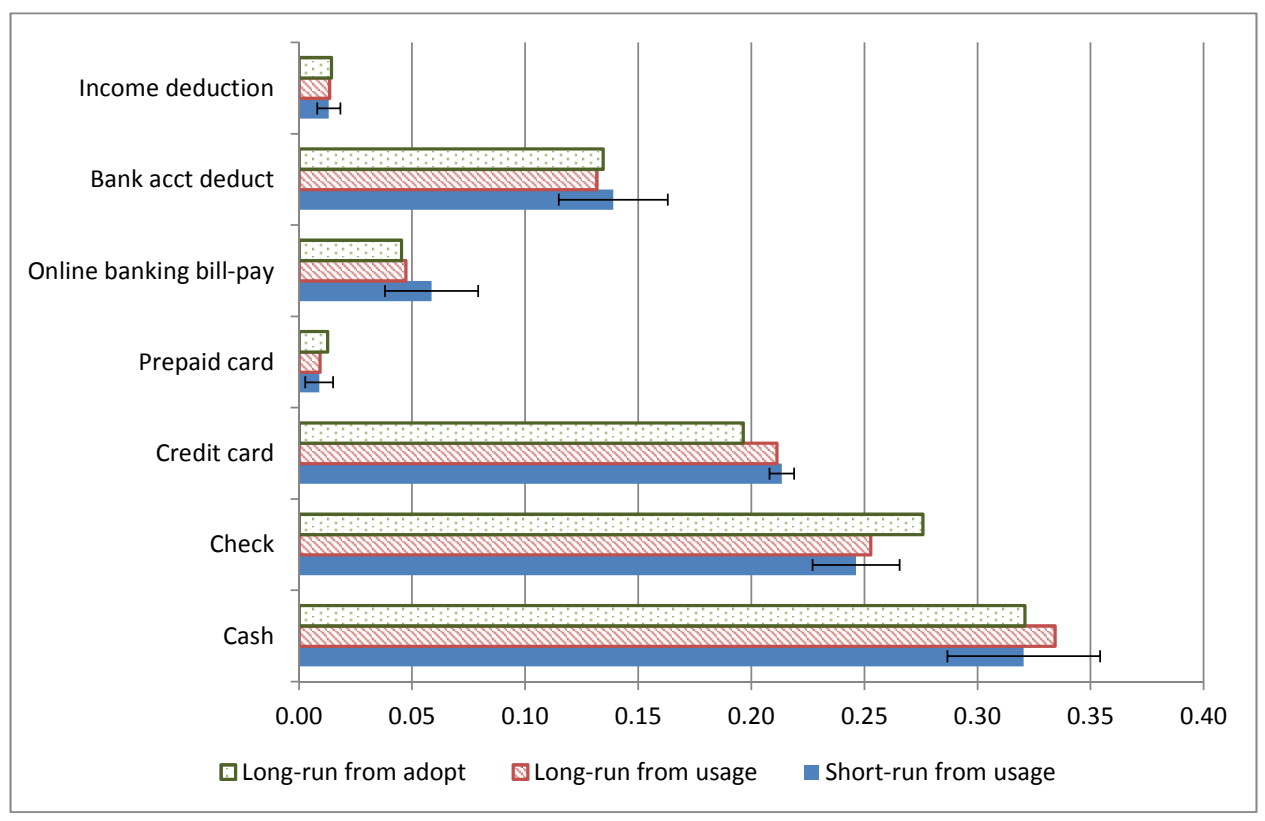

Figure 1: Changes in use of each payment instrument, measured as market share percentage points, in response to a decrease in debit card usage value and an increase in adoption cost, by adoption adjustment (short run or long run).

use check. We explore income differences further below. But overall, we find little difference in the response to usage value and adoption costs.

Also, despite the importance of selection, our model predicts that the long-run and short-run effects of a change in the usage value of debit are very similar. There is 5 a slightly higher substitution towards cash in the long-run, as consumers drop their debit card. This similarity between long and short-run results follows from the fact that some consumers already hold substitute products and those that do not face large adoption costs. That is, the long-run response is concentrated on those who already hold other instruments, and those consumers can also respond in the shortrun. That does not mean that adoption is unimportant. We show in what follows that adoption is central for understanding several results.

Thus, the main results of Figure 1 are that a change in the usage value of debit leads to a substantial substitution towards paper products, and that this result differs little in the long and short-run. A change in adoption costs finds similar results.

It is perhaps surprising that paper products do so well, and in particular that checks emerge as a stronger substitute to debit cards than credit cards. However, other studies of payment choice also provide evidence that debit cards and paper 
instruments are closely related. Garcia Swartz, Hahn, and Layne-Farrar (2006) consider the evolution of usage of debit, credit, cash and check in a nationwide grocery store chain, and find that debit cards pick up a large portion of the decline in cash and check that happened in the recent years (see Figure 2 in their study). More direct 5 evidence comes from Borzekowski and Kiser (2008), who report that 48.5 percent of respondents in a nationally representative survey indicated that for them, debit serves as a substitute for cash, and about 32 percent of respondents said they used debit instead of checks. In a European survey, as reported by Bolt, Jonker, and Van Renselaar (2010), respondents were asked about their reaction to a transaction fee on debit card use, and $65 \%$ indicated they would pay with cash instead (there was no checks option).

What explains this result in our data? While part of the substitutability of check and debit might be that they have similar liquidity characteristics, we find that an important element of the explanation is how payment instruments are used in different contexts. In particular, check dominates as a substitute in bill-pay contexts, whereas credit cards are a stronger substitute in retail contexts.

In order to make this point, Figure 2 breaks up the short-run response to a change in the usage value of debit cards into the change in the retail context (summing over on-line, essential and non-essential retail, as well as other) and the change in the bill-pay context (summing over the automatic, on-line and in-person/mail bill-pay contexts). In this figure, the two bars for each instrument sum to the short-run line in Figure 1. Thus, the sum of all the lines in Figure 2 is one.

In Figure 2, we see that retail follows the expected pattern. Cash is, again, by far the strongest substitute to debit cards, but credit cards now take the second 25 place, followed by checks. The rank reversal of credit and checks in the retail sector is intuitive. Furthermore, as we show below, the check use in retail stems in part from consumers that do not hold credit cards, or else check use would be even lower. Also, Ching and Hayashi (2010) consider the effect of removing reward programs on debit (analagous to our increase in disutility of debit), and find that in the retail context, credit card shows a stronger response than paper products (cash and checks combined).

Although credit card is a stronger substitute to debit than check in the retail sector, we see that check is the leading substitute in the bill-pay sector. Bank account deduction is also important. Credit card does poorly here, in part because it is low 


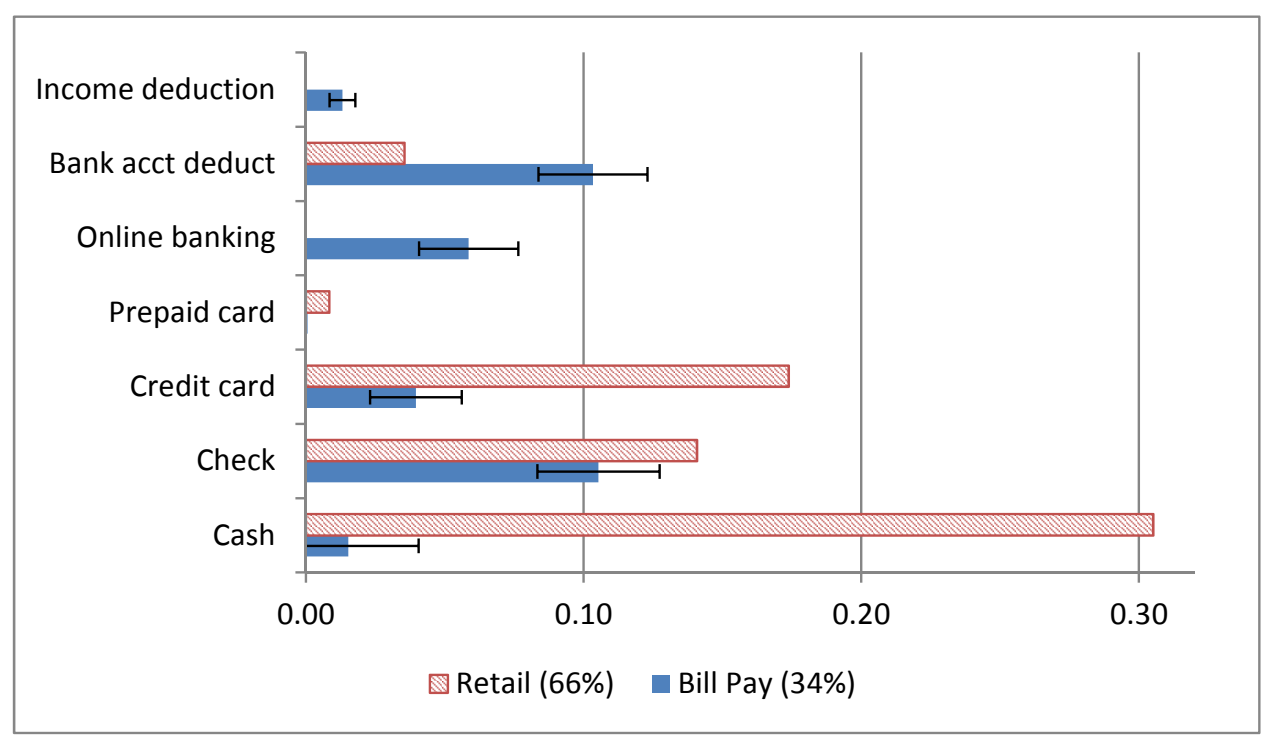

Figure 2: Short-run changes in market share percentage points in response to an increase in debit card use cost, by bill-pay and retail contexts.

income consumers that use debit cards to pay bills, and these consumers do not hold credit cards, and also because credit cards face strong substitutes (checks or bank account deduction) in each bill-pay context. Indeed, Hayashi and Klee (2003) use a different survey to point out a large reduction in the share of credit card between 5 retail and bill-pay contexts (see Tables 2(a) and 2(b) in their study).

In interpreting retail and bill-pay results, it is important to keep in mind that check is the only bill-pay option that all consumers hold, while the adoption of other instruments varies. Recall from Table 3 that our data show substantial use of debit cards to pay bills. The popularity of check in the bill-pay sector means that overall, it is a stronger substitute to debit than credit cards. Bill-pay also explains the otherwise surprising result that bank account deduction is a substitute to debit. Bank account deduction gains 13-14\% in each experiment in Figure 1, and similarly Hayashi and Klee (2003) also report a strong relationship between direct deposit and debit in billpay contexts. This analysis highlights the importance of our study design and data set, which incorporates both adoption and usage, and recognizes that the substitution between payment options may change across retail and bill-pay contexts.

Note that in our counterfactual analysis, we see some substitution of payments from retail to bill-pay. Since debit is primarily a retail instrument, consumers in our model find retail less attractive as debit declines in value. Allowing this sort of 
substitution is an important element of our model, since in some cases, consumers may choose to pay for something in a retail or bill-pay format based on their payment instrument. For example, a consumer without a credit card may purchase an item or subscription via installments. However, some readers may find such substitution we estimated our model with a nested logit version of the usage stage, in which billpay and retail are separate nests. In this specification, the importance of the nests (the inclusive parameter) is identified by the extent to which consumers maintain a constant level of bill-pay and retail payments, despite different preferences and holdings.

Remarkably, we found that the nesting was unimportant, and results were very close to our original logit specification. This may be a result of the rich correlation matrix that we specify, so the nested logit specification adds little new explanatory power to the model. We also estimated a model in which consumers could not sub15 stitute between bill-pay and retail. The results were almost identical to Figure $1 .^{25}$ Thus, we view the results on the importance of check as a substitute to debit as robust to several modeling approaches.

We now turn to the heterogeneity of our results across socio-economic class, which we find is substantial. In order to show this, we predict outcomes from our model for different consumers. We consider two hypothetical consumers, a high-income consumer and a low-income consumer. The high-income consumer is a college graduate and has an annual income of $\$ 80,000$. The low-income consumer has a high school degree and an annual income of $\$ 30,000$. Otherwise, they are identical, with average values in the data for other variables. We assume that they each hold every instrument, and we graph the response to a decrease in the usage value of debit.

We see very large differences in Figure 3, with the high-income consumer shifting market share to credit card by almost 16 percentage points more than the low-income consumer. The low-income consumer shifts to cash more than the high-income consumer by 9 percentage points, and cash and check together by 15 percentage points.

\footnotetext{
${ }^{25}$ Note that the specification in which consumers could not substitute between bill-pay and retail is difficult to interpret since it requires two assumptions about the potential number of transactions, the number for bill-pay and the number for retail. Similarly, normalizing the outside option to bill-pay and retail to zero assumes that the outside options to both categories are equal to each other. This matters for our counterfactual, since our experiment consists of altering the value of debit relative to the outside option. Given the similarity in results to our favored specification, we did not further pursue these issues.
} 


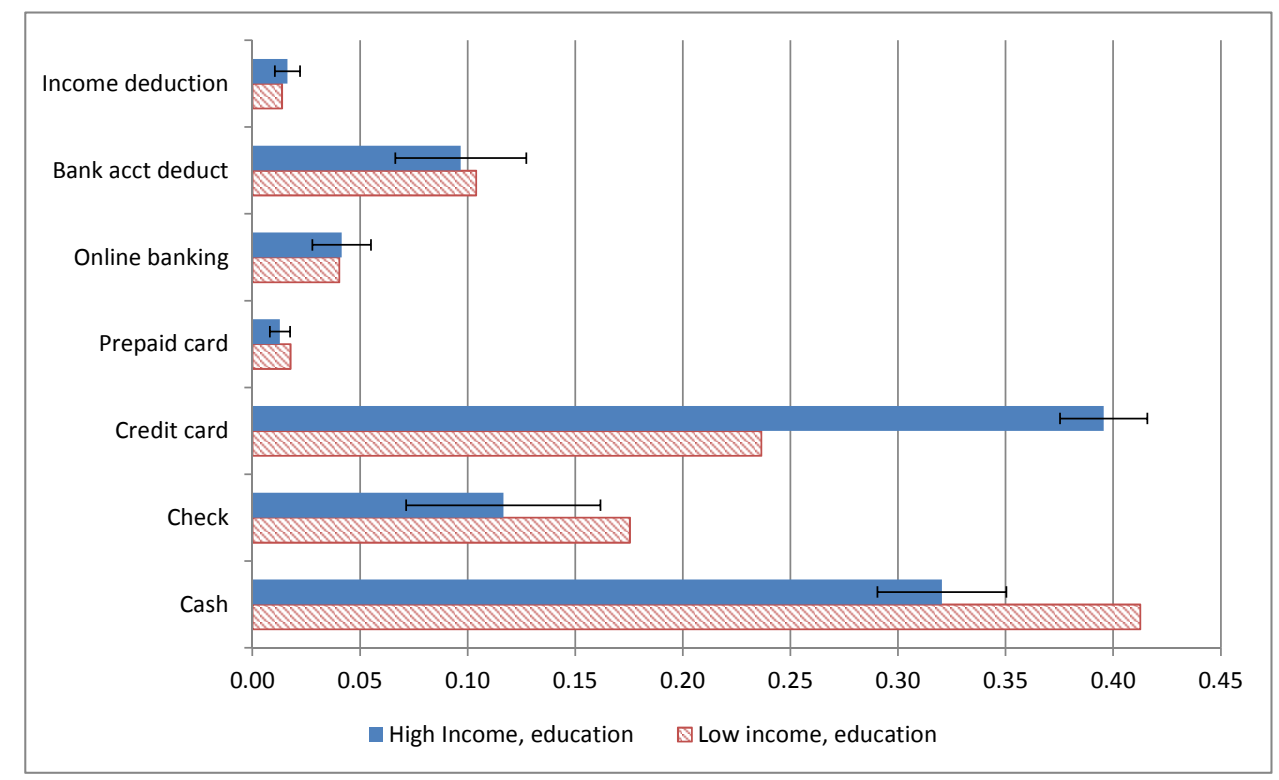

Figure 3: Changes in market share percentage points in response to an decrease in the usage value of debit, assuming consumers hold all instruments.

Note also that, different from Figure 1, credit cards are more popular than check for both consumers. The explanation is that we have assumed that both consumers hold each payment instrument, whereas the differences in Figure 1 were in part due to different holdings. Naturally, the differences in Figure 3 would be even larger if 5 we started with a more realistic scenario, where the wealthy consumer held more instruments than the poorer one.

Finally, we consider the effect on consumer welfare from these interventions, graphed in Figure 4 for annual incomes greater than $\$ 7,500$. The long-run welfare cost of the change in the usage value of debit is estimated to be between -2.8 percent and -1.3 percent, compared to the initial welfare level, depending on the income. In the short run, before adoption choices can respond, the welfare loss is substantially larger, about 7 percent to 30 percent larger, with larger effects for low income consumers. The difference over the income range is striking, with welfare falling more than twice as much for consumers from low-income consumers than for consumers from the wealthiest consumers in the long run, and 2.5 times as much in the short run. Wealthy consumers fare better because they typically have adopted larger bundles to begin with, so it is easier for them to substitute in the short run, and because there is less adjustment (and, because they are wealthy, less costly adjustment) in 


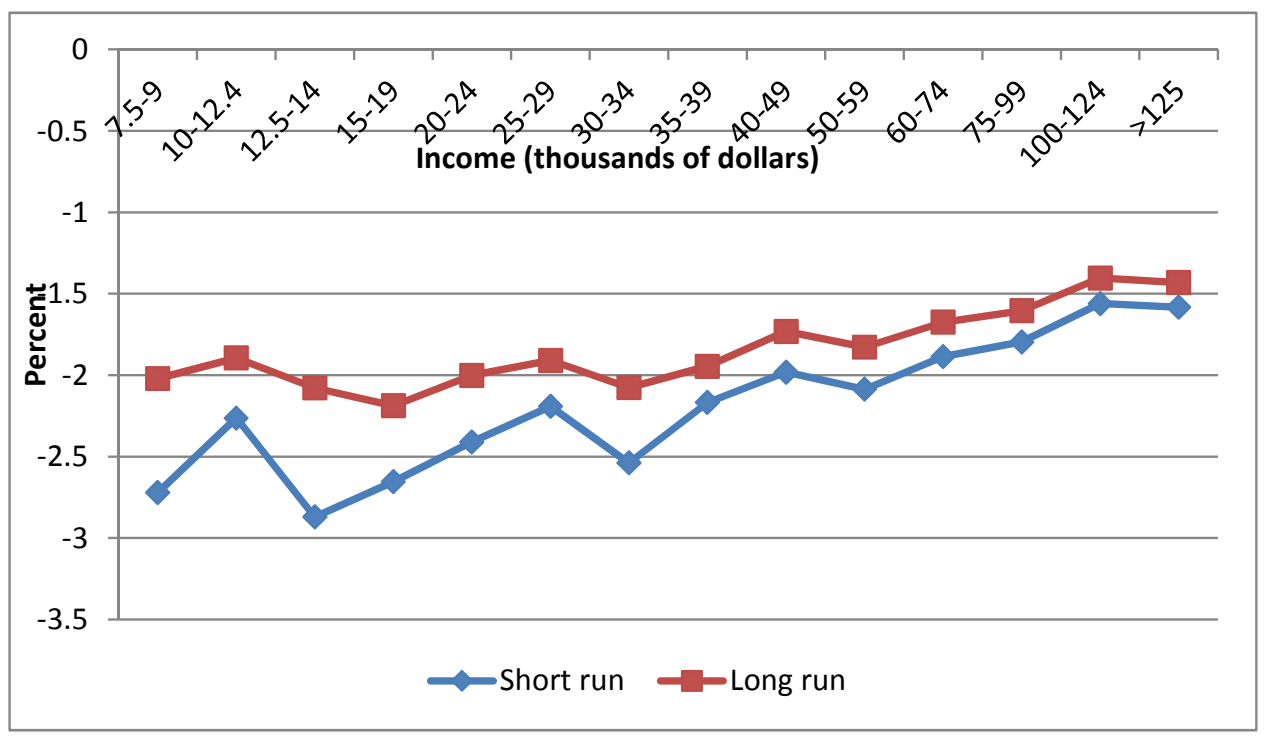

Figure 4: Welfare change from a decrease in the usage value of debit, by income category.

the long run. ${ }^{26}$

Interestingly, our estimated model requires a substantially larger change in adoption cost than usage value in order to implement the same change in the share of debit cards. Whereas even a small change in usage value causes a change in share,

5 a change in adoption cost does not affect market shares unless it induces consumers to drop their debit card entirely. If we compare small changes in usage value and adoption cost that have the same welfare effect, the change in adoption cost has a more even effect across income since it induces little change in behavior.

We are interested in placing a dollar value on these changes in utility. Because our survey data does not offer any variation in an explicit price of use for payment instruments, we turn to estimates made by other studies. Two studies offer evidence on the own-price semi-elasticity of debit, one at 3.9 cents and another at 3.6 cents. Such is the per-transaction fee on debit use that will reduce the share of debit by 1 percentage point. ${ }^{27}$ Taking the latter estimate, our welfare results imply that a 3.6

\footnotetext{
${ }^{26}$ As stated above, we do not incorporate the merchant response to recent regulation either in terms of acceptance or pricing, and we do not study the ways in which regulation will affect bank pricing or consumer banking choices.

${ }^{27}$ Bolt, Jonker, and Van Renselaar (2010) present an estimate of the own-price semi-elasticity of debit card use: 3 euro cents, or $3^{*} 1.3=3.9$ cents, for 1 percentage point change in the market share of debit. In the US context, Borzekowski, Kiser, and Ahmed (2008) offer a remarkably similar estimate: 75 cents drives the share of debit down by 21 percentage points, or 3.6 cents for 1 percentage point.
} 
cent per-transaction fee on debit leads to a 1-3\% drop in the welfare.

By making some further assumptions, we can place a dollar value on the welfare drop. In particular, suppose we model the usage value $\delta_{i j c}$ as linear in the price of using instrument $j$, so for instance, $\delta_{i j c}=\tilde{\delta}_{i j c}-\beta_{p} p_{j}$, where $p_{j}$ is the price of instrument

${ }_{5} j, \beta_{p}$ is the price coefficient and $\tilde{\delta}_{i j c}$ is whatever part of $\delta_{i j c}$ does not depend on price. Although we observe no variation in $p_{j}$, we can interpret Borzekowski, Kiser, and Ahmed (2008) to say that $\Delta$ (which we have computed) corresponds to a change in $p_{j}$ of 3.6 cents, and thus $\beta_{p}=\Delta / 3.6$. With this marginal utility of income, we divide welfare by $\beta_{p}$ to get a welfare estimate in dollars. Among consumers that hold debit 10 cards, we find that an increase in price of 3.6 cents per transaction leads to a decline in welfare of 0.2008 cents per payment opportunity, which corresponds to a welfare decrease of 78.3 cents per month.

\subsection{Credit cards}

Now we turn to credit cards, motivated by recent policy actions that would allow for 15 merchant surcharging of card products. ${ }^{28}$ Because surcharging acts as a usage fee, we study changes to usage values for credit cards. Similar to our study of debit cards, we alter the usage value of credit cards enough to change the market share for credit card by one percentage point, and then calculate changes in market shares for the other products assuming consumers do not switch to the outside option.

The result appears in Figure 5. Among all credit card holders, substitution appears about evenly split between cash, check and debit, each with between 25 and $27 \%$ market share, with bank account deduction capturing $15 \%$. The strong showing of paper products is surprising and is at odds with results by Arango, Huynh, and Sabetti (2015), who find the effect on cash to be small, with debit picking up most of the decline in credit (although they do not present results on checks). In part, this result highlights the importance of accounting for bill-pay contexts. However, Ching and Hayashi (2010) consider the effect of removing credit card rewards in a retail context and find results that similar to ours: the shares of debit and of paper products (checks and cash combined) increase to a similar magnitude.

\footnotetext{
${ }^{28}$ We focus on credit cards, but note that the legal implications of these policies apply to credit and debit cards equally. Merchants can surcharge either type. However, since credit cards typically carry higher merchant fees, we expect that these developments will lead primarily towards making credit more expensive than other payment instruments.
} 


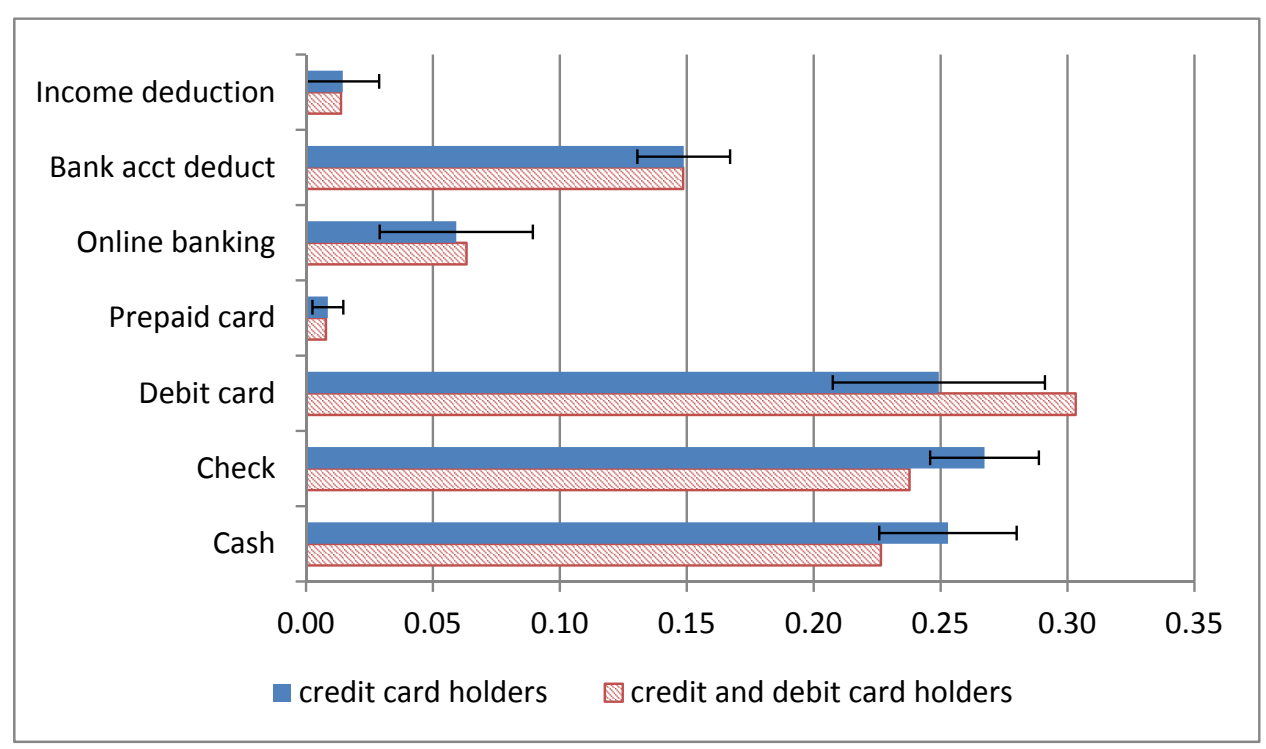

Figure 5: Changes in market share percentage points in response to an decrease in the usage value of credit cards.

When we look only at those consumers that also hold a debit card, debit does substantially better. Debit gains 30\%, more than 6 percentage points better than cash or check. Again, check's strong showing mostly comes from bill-pay contexts. In separate calculations, we find that bill-pay accounts for $43 \%$ of check's market share 5 change, whereas bill-pay accounts for only $23 \%$ of debit's market share change.

Substitution patterns may be broadly similar for debit and credit cards, but welfare calculations exhibit important differences. We present the percentage change in welfare by income category. In Figure 6, we see that welfare decreases between 1.5 and $3 \%$ in the short-run, with a long-run high around $2.5 \%$. However, the pattern is different from the debit card case because the welfare decrease is proportionally larger for wealthy people. Whereas consumers with incomes less than $\$ 40,000$ experience decreases less than $1.5 \%$ in the long-run, we find that consumers above $\$ 125,000$ face decreases close to $2.5 \%$. Naturally, this arises because wealthy people are more likely to hold and use credit cards.

\section{${ }_{15} 9$ Conclusion}

In this paper, we specify a new model of adoption and use of payment instruments, such as credit cards, debit cards, and prepaid cards. Our model addresses features 


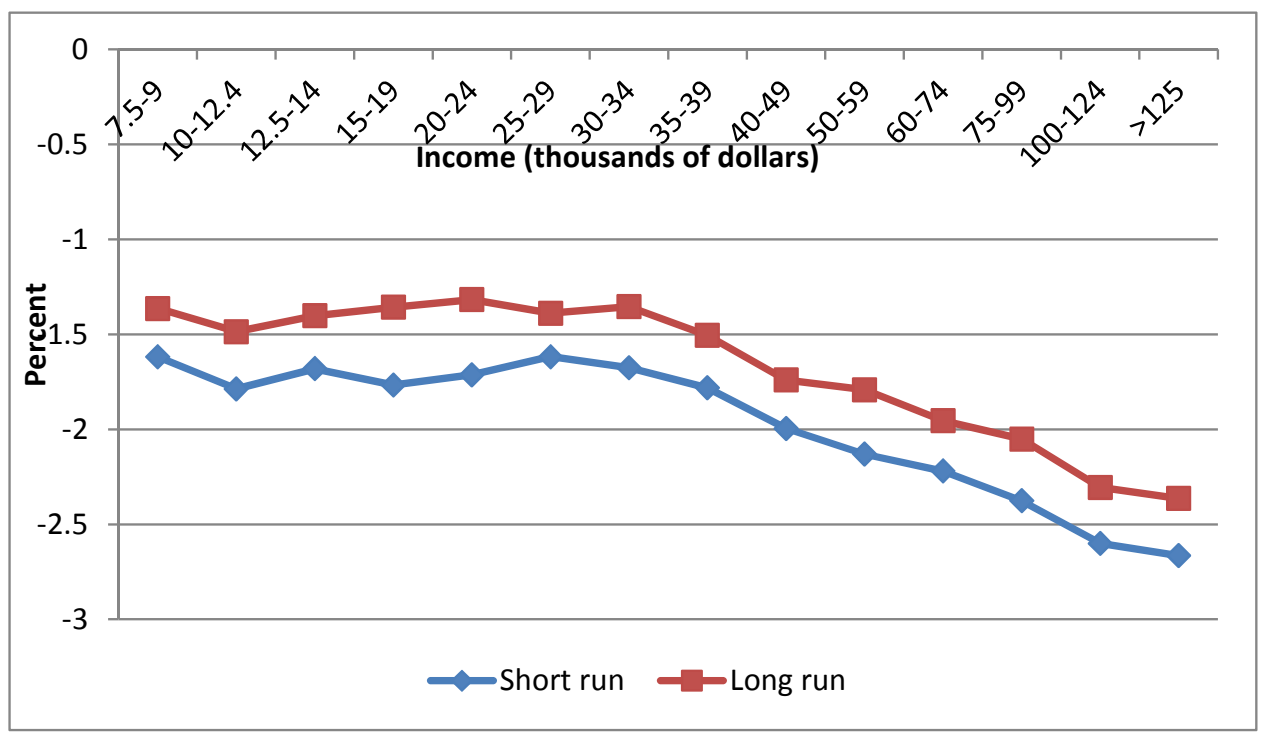

Figure 6: Welfare change from a change in the usage value of credit, by income category.

of the discrete-continuous nature of the problem in a way that is more rigorous and flexible (in that we allow for the agent to know more than the econometrician, and we identify the structural effect of the continuous choice on the discrete choices) than the previous literature. We achieve identification through exclusion restrictions on 5 which consumer preferences affect usage and adoption. We also discuss identification of the bundled nature of the problem.

Using new data available from the Federal Reserve Bank of Boston, we estimate the model. We find a number of interesting results about the determinants of payment choice, such as the role of age and income. We compute demand elasticities to the cost of debit cards and find substantial switching of payment methods, particularly to paper-based methods such as cash and check. We show that responses vary with demographics, particularly income and education, and by context such as bill-pay and retail. We find that the welfare effects of reducing the usage value of debit cards are larger for low-income, low education consumers, whereas reducing the value of credit cards hurts wealthy consumers more than poorer ones.

Our study provides perspective on one feature of the potential response to interchange fee and surcharging regulation, and thus serves to inform future policy in this area. There are several other dimensions of response to these policies, so these interventions provide a complex policy question towards which we contribute. 


\section{References}

Amromin, Gene, and Sujit Chakravorti. 2009. "Whither Loose Change? The Diminishing Demand for Small-Denomination Currency." Journal of Money, Credit and Banking 41: $315-335$.

5 Arango, Carlos, Kim Huynh, and Leonard Sabetti. 2015. "How Do You Pay? The Role of Incentives at the Point-of-Sale." In Press, Journal of Banking and Finance.

Berry, Steven, James Levinsohn, and Ariel Pakes. 1995. "Automobile Prices in Market Equilibrium." Econometrica 63: 841-890.

Bolt, Wilko, Nicole Jonker, and Corry Van Renselaar. 2010. "Incentives at the Counter: An Empirical Analysis of Surcharging Card Payments and Payment Behaviour in the Netherlands." Journal of Banking \& Finance 34: 1738-1744.

Borzekowski, Ron, and Elizabeth K. Kiser. 2008. "The Choice at the Checkout: Quantifying Demand Across Payment Instruments." International Journal of Industrial Organization 26: 889-902.

Borzekowski, Ron, Elizabeth K. Kiser, and Shaista Ahmed. 2008. "Consumers' Use of Debit Cards: Patterns, Preferences, and Price Response." Journal of Money, Credit and Banking 1: 149-172.

Bradford, Terri, and Fumiko Hayashi. 2008. "Developments in Interchange Fees in the United States and Abroad." Payment System Research Briefing, Federal Reserve Bank of Kansas City, April. http://www.kansascityfed.org/Publicat/PSR/ Briefings/PSRBriefingApr08.pdf.

Burda, Martin, Mathew C. Harding, and Jerry A. Hausman. 2012. "A Poisson Mixture Model of Discrete Choice." Journal of Econometrics 166: 184-203.

Carbo-Valverde, Santiago, Sujit Chakravorti, and Francisco Rodriguez-Fernandez. 2015.

"The Role of Interchange Fees in Two-sided Markets: An Empirical Investigation on Payment Cards." Forthcoming, Review of Economics and Statistics.

Carbo-Valverde, Santiago, Jose Manuel Linares-Zegarra, and Francisco RodriguezFernandez. 2012. "Feedback Loop Effects in Payment Card Markets: Empirical Evidence." Review of Network Economics 11. 
Ching, Andrew T., and Fumiko Hayashi. 2010. "Payment card rewards programs and consumer payment choice." Journal of Banking and Finance 34: 1773 - 1787.

Cohen, Michael, and Marc Rysman. 2012. "Payment Choice with Consumer Panel Data." Unpublished Manuscript, Boston University.

5 Crawford, Gregory S., and Ali Yurukoglu. 2012. "The Welfare Effects of Bundling in MultiChannel Television Markets." American Economic Review 102: 643-685.

Dube, Jean-Pierre. 2004. "Multiple Discreteness and Product Differentiation: Demand for Carbonated Soft Drinks." Marketing Science 23: 66-81.

Dubin, Jeffrey A., and Daniel L. McFadden. 1984. "An Econometric Analysis of Residential Electric Appliance Holdings and Consumption." Econometrica 52: 345-362.

Foster, Kevin, Erik Meijer, Scott Schuh, and Michael A. Zabek. 2009. "The 2008 Survey of Consumer Payment Choice." Public Policy Discussion Paper No. 09-10, Federal Reserve Bank of Boston.

Garcia Swartz, Daniel D., Robert W. Hahn, and Anne Layne-Farrar. 2006. "The Move Toward A Cashless Society: A Closer Look at Payment Instrument Economics." Review of Network Economics 5: 199-228.

Gentzkow, Matthew. 2007. "Valuing New Goods in a Model with Complementarity: Online Newspapers." American Economic Review 97: 713-744.

Gourieroux, Christian, and Alain Montfort. 1996. Simulation-Based Econometric Methods. Oxford University Press.

Hagiu, Andrei, and Julian Wright. 2015. "Multi-sided Platforms." forthcoming, International Journal of Industrial Organization.

Hanemann, W. Michael. 1984. "Discrete/Continuous Models of Consumer Demand." Econometrica 52: 541-561.

Hayashi, Fumiko, and Elizabeth Klee. 2003. "Technology adoption and consumer payments: Evidence from survey data." Review of Network 2: 2.

Heckman, James J. 1979. "Sample Selection Bias as a Specification Error." Econometrica 47: $153-161$. 
Hendel, Igal. 1999. "Estimating Multiple-Discrete Choice Models: An Application to Computerization Returns." The Review of Economic Studies 66: 423-446.

Klee, Elizabeth. 2008. "How People Pay: Evidence from Grocery Store Data." Journal of Monetary Economics 55: 526-541.

5 Moulton, Brent Richard. 1990. "An Illustration of a Pitfall in Estimating the Effects of Aggregate Variables on Micro Unit." Review of Economics and Statistics 72: 334-338.

Nevo, Aviv. 2001. "Measuring Market Power in the Ready-to-Eat Breakfast Cereal Industry." Econometrica 69: 307-342.

Pakes, Ariel, and David Pollard. 1989. "Simulation and the Asymptotics of Optimization Estimators." Econometrica 57: 1027-1057.

Rochet, J.-C., and Jean Tirole. 2006. "Two-Sided Markets: A Progress Report." RAND Journal of Economics 37: 645-667.

Rochet, Jean-Charles, and Jean Tirole. 2002. "Cooperation Among Competitors: Some Economics of Payment Card Assocations." RAND Journal of Economics 33: 549-570.

15 Ryan, Stephen P., and Catherine Tucker. 2012. "Heterogeneity and the Dynamics of Technology Adoption." Quantitative Marketing and Economics 10: 63-109.

Rysman, Marc. 2007. "Empirical Analysis of Payment Card Usage." Journal of Industrial Economics 60: 1-36.

Rysman, Marc. 2009. "The Economics of Two-Sided Markets." Journal of Economic Perspectives 23: 125-144.

Rysman, Marc. 2010. "Consumer Payment Choice: Measurement Topics." In The Changing Retail Payments Landscape: What Role for Central Banks? An International Payment Policy Conference, 61-81. Federal Reserve Bank of Kansas City.

Rysman, Marc, and Julian Wright. 2015. "The Economics of Payment Cards." forthcoming, Review of Newtork Economics.

Schuh, Scott, Oz Shy, Joanna Stavins, and Robert Triest. 2012. "An Economic Analysis of the 2011 Settlement Between the Department of Justice and Credit Card Networks." Journal of Competition Law \& Economics 8: 107-144. 
Schuh, Scott, and Joanna Stavins. 2010. "Why Are (Some) Consumers (Finally) Writing Fewer Checks? The Role of Payment Characteristics." Journal of Banking and Finance 34: $1745-1758$.

Schuh, Scott, and Joanna Stavins. 2013. "How Consumers Pay: Adoption and Use of 5 Payments." Accounting and Finance Research 2: 1-21.

Schuh, Scott, Joanna Stavins, and Oz Shy. 2010. "Who Gains and Who Loses from Credit Card Payments? Theory and Calibrations." Public Policy Discussion Paper No. 10-3, Federal Reserve Bank of Boston.

Shy, Oz, and Joanna Stavins. 2014. "Merchant Steering of Consumer Payment Choice: Evidence from a 2012 Diary Survey." Federal Reserve Bank of Boston Working Paper $14-1$.

Train, Kenneth E. 2003. Discrete Choice Methods with Simulation. Cambridge University Press.

Verdier, Marianne. 2011. "Interchange Fees in Payment Card Systems: A Survey of the Literature." Journal of Economic Surveys 25: 273-297.

Wang, Zhu, and Alexander F. Wolman. 2014. "Payment Choice and the Future of Currency: Insight from Two Billion Retail Transactions." Working Paper 14-09R, Federal Reserve Bank of Richmond.

Weiner, Stuart, and Julian Wright. 2005. "Interchange Fees in Various Countries: Developments and Determinants." Review of Network Economics 4: 290-323.

Weyl, E. Glen. 2010. "A Price Theory of Multi-Sided Platforms." American Economic Review 100: 1642-1672.

Yang, Botao, and Andrew Ching. 2014. "Dynamics of Consumer Adoption of Financial Innovation: The Case of ATM Cards." Management Science 60: 903-922.

\section{${ }_{25}$ Appendix}

This section presents the estimates from the covariance matrix $\Sigma$. Table 11 presents the coefficients on the standard normal shocks for usage that we draw. The coefficients on 
instrument shocks are comparable in size to those on context shocks. The bottom panel presents the extra shocks that we built around the debit choice. The fact that the debit and credit coefficients in the debit-credit shock are of opposite sign implies a negative covariance in the use of these instruments, suggesting that heavy users of one rarely switch to the other.

5 Cash and debit appear as close substitutes here.

Table 12 presents the standard deviation in usage for each context and instrument. The entries in this table are made up of the coefficients in Table 11. Note that this is the variance due to the terms $\nu$ and $\omega$ in our model. That is, this is the information known to the consumer that is not observed by the researcher. All of the magnitudes are comparable in size, so no one entry in the table stands out. However, it appears that the on-line retail context has the most heterogeneity and that cash use has the least, which seems reasonable.

In addition, we allow for correlation between the adoption and usage stage. Rather than present the underlying parameters, we present the correlations in Table 13. Although the parameters that generate the selection effect vary only by instrument, the resulting correlations differ by context as well since context-level variance affects the correlation between instrument adoption and instrument usage. Thus, Table 13 presents correlation terms by context and instrument. We see that there are important selection effects, particularly for debit. Selection is very high for prepaid cards, which indeed serve a specialized population. 


\begin{tabular}{lrrrr}
\hline & Use only & model & Full model \\
\hline Instrument-specific shock & & & & \\
\hline Cash & 0.60 & $(0.01)$ & 0.001 & $(0.00)$ \\
Check & 0.26 & $(0.01)$ & 0.13 & $(0.01)$ \\
Debit card & 1.04 & $(0.01)$ & 0.96 & $(0.01)$ \\
Credit card & 1.00 & $(0.01)$ & 0.89 & $(0.01)$ \\
Prepaid card & 0.78 & $(0.03)$ & 0.81 & $(0.03)$ \\
Online banking & 0.07 & $(0.02)$ & 0.45 & $(0.01)$ \\
Bank acct. deduct & 5.19 & $(0.46)$ & 1.10 & $(0.11)$ \\
Income deduction & 0.03 & $(0.17)$ & 0.30 & $(0.04)$ \\
\hline Context-specific shocks & & & & \\
\hline Automatic bill pay & 0.76 & $(0.01)$ & 0.87 & $(0.02)$ \\
Online bill pay & 0.71 & $(0.02)$ & 0.72 & $(0.01)$ \\
In person/mail bill pay & 0.82 & $(0.02)$ & 0.64 & $(0.01)$ \\
Online retail & 1.03 & $(0.02)$ & 1.01 & $(0.02)$ \\
Essential retail & 0.10 & $(0.01)$ & 0.16 & $(0.01)$ \\
Non-essential retail & 0.47 & $(0.01)$ & 0.56 & $(0.01)$ \\
Other & 0.07 & $(0.01)$ & 0.04 & $(0.01)$ \\
\hline Common shocks (coefs) & & & & \\
\hline Cash (debit - cash) & -0.78 & $(0.01)$ & $0.89(0.01)$ \\
Debit card (debit - cash) & -0.32 & $(0.01)$ & 0.62 & $(0.01)$ \\
Debit card (debit - credit) & -0.73 & $(0.01)$ & 0.14 & $(0.01)$ \\
Credit card (debit - credit) & -0.01 & $(0.01)$ & -0.67 & $(0.01)$ \\
Check (debit - check) & 0.90 & $(0.01)$ & 1.00 & $(0.01)$ \\
Debit card (debit - check) & 0.34 & $(0.01)$ & -0.02 & $(0.01)$ \\
\hline
\end{tabular}

Table 11: Coefficients on shocks that govern the correlation matrix.

\begin{tabular}{|c|c|c|c|c|c|c|c|}
\hline & \multicolumn{3}{|c|}{ Bill Pay } & \multicolumn{3}{|c|}{ Retail } & \multirow[b]{2}{*}{ Other } \\
\hline & Automatic & Online & Mail/In person & Online & Essential & Non-essential & \\
\hline \multirow[t]{2}{*}{ Cash } & & & 1.10 & & 0.91 & 1.05 & 0.89 \\
\hline & & & $(0.01)$ & & $(0.01)$ & $(0.01)$ & $(0.01)$ \\
\hline \multirow[t]{2}{*}{ Check } & & & 1.20 & 1.43 & 1.02 & 1.15 & 1.01 \\
\hline & & & $(0.01)$ & $(0.01)$ & $(0.01)$ & $(0.01)$ & $(0.01)$ \\
\hline \multirow[t]{2}{*}{ Debit card } & 1.44 & 1.35 & 1.32 & 1.53 & 1.16 & 1.28 & 1.15 \\
\hline & $(0.01)$ & $(0.01)$ & $(0.01)$ & $(0.01)$ & $(0.01)$ & $(0.01)$ & $(0.01)$ \\
\hline \multirow[t]{2}{*}{ Credit card } & 1.41 & 1.32 & 1.29 & 1.51 & 1.13 & 1.25 & 1.12 \\
\hline & $(0.01)$ & $(0.01)$ & $(0.01)$ & $(0.01)$ & $(0.01)$ & $(0.01)$ & $(0.01)$ \\
\hline \multirow[t]{2}{*}{ Prepaid card } & & & 1.28 & 1.50 & 1.12 & 1.24 & 1.10 \\
\hline & & & $(0.10)$ & $(0.08)$ & $(0.11)$ & $(0.10)$ & $(0.11)$ \\
\hline \multirow[t]{2}{*}{ Online banking } & & 1.08 & & & & & \\
\hline & & $(0.03)$ & & & & & \\
\hline \multirow[t]{2}{*}{ Bank acct. deduct. } & 0.98 & 0.85 & & 1.11 & & & \\
\hline & $(0.02)$ & $(0.01)$ & & $(0.02)$ & & & \\
\hline \multirow[t]{2}{*}{ Income deduction } & 0.92 & & & & & & \\
\hline & $(0.02)$ & & & & & & \\
\hline
\end{tabular}

Table 12: Standard deviation of correlation matrix $\Sigma$, by instrument and context. 


\begin{tabular}{|c|c|c|c|c|c|c|c|}
\hline & \multicolumn{3}{|c|}{ Bill Pay } & \multicolumn{3}{|c|}{ Retail } & \multirow[b]{2}{*}{ Other } \\
\hline & Automatic & Online & Mail/In person & Online & Essential & Non-essential & \\
\hline \multirow[t]{2}{*}{ debit card } & & & 0.73 & & 0.83 & 0.75 & 0.83 \\
\hline & & & $(0.44)$ & & $(0.49)$ & $(0.45)$ & $(0.50)$ \\
\hline \multirow[t]{2}{*}{ credit card } & & & 0.69 & 0.59 & 0.79 & 0.71 & 0.80 \\
\hline & & & $(0.49)$ & $(0.42)$ & $(0.56)$ & $(0.50)$ & $(0.56)$ \\
\hline \multirow[t]{2}{*}{ online banking } & & 0.75 & & & & & \\
\hline & & $(0.55)$ & & & & & \\
\hline \multirow[t]{2}{*}{ prepaid card } & & & 0.86 & 0.74 & 0.99 & 0.89 & 1.00 \\
\hline & & & (0.59) & $(0.50)$ & $(0.67)$ & $(0.61)$ & $(0.68)$ \\
\hline \multirow[t]{2}{*}{ bank acct. deduct. } & 0.46 & 0.54 & & 0.41 & & & \\
\hline & $(0.44)$ & $(0.50)$ & & $(0.38)$ & & & \\
\hline \multirow[t]{2}{*}{ income deduction } & 0.32 & & & & & & \\
\hline & $(0.33)$ & & & & & & \\
\hline
\end{tabular}

Table 13: Correlation between instrument adoption and usage, by instrument and context.

\begin{tabular}{|c|c|}
\hline Cash & Also called currency. Includes coins, Federal Reserve notes, and other paper bills. \\
\hline Check & $\begin{array}{l}\text { A draft piece of paper directing a bank or other financial institution to pay a specific } \\
\text { amount of money from a demand deposit account as instructed to a person or } \\
\text { business. }\end{array}$ \\
\hline Debit card & $\begin{array}{l}\text { Also called a check card. A type of card that allows the cardholder to make a } \\
\text { payment that is deducted directly from a bank account at the time of purchase or bill } \\
\text { payment. Often these cards have a Visa or MasterCard logo, but they are not a credit } \\
\text { card. A debit card also works as an ATM card. }\end{array}$ \\
\hline Credit card & $\begin{array}{l}\text { Also called a charge card. A type of card that authorizes the cardholder to make a } \\
\text { purchase by granting a line of credit that will be paid back to the card company at a } \\
\text { later date, possibly in installments. Examples include: Visa, MasterCard, Discover, } \\
\text { American Express, and cards branded by retail, gasoline, or other companies. }\end{array}$ \\
\hline Prepaid card & $\begin{array}{l}\text { Also called a stored value card or gift card. A type of card that can be used for } \\
\text { payments up to the amount of money stored (or loaded) on the card. Often these } \\
\text { cards will have a Visa or MasterCard logo, but they are not a credit card or debit } \\
\text { card. Examples include: general purpose, specific purpose (retailers, telephone, } \\
\text { public transportation, etc.), payroll cards, and electronic benefits transfer (EBT). }\end{array}$ \\
\hline $\begin{array}{l}\text { Electronic bank } \\
\text { account deduction } \\
\text { (EBAD) }\end{array}$ & $\begin{array}{l}\text { An electronic payment made directly from a bank account and initiated by a } \\
\text { consumer who provides a bank account number and bank routing number to a non- } \\
\text { bank third party via the Internet, verbally, or in writing. This payment is made } \\
\text { without using a paper check or payment card, and can be automatic or processed as } \\
\text { needed. Examples include: automatic bill payment, bill payment made online at a } \\
\text { company's web site (but not using online banking bill payment), other online } \\
\text { payment, or payment made directly from income. }\end{array}$ \\
\hline $\begin{array}{l}\text { Online banking } \\
\text { bill pay (OBBP) }\end{array}$ & $\begin{array}{l}\text { A bill payment made directly from a bank account and initiated by a consumer } \\
\text { using the bank's online banking bill payment function on the bank's website via the } \\
\text { Internet or a mobile banking application. This payment is made without using a } \\
\text { paper check or payment card, and can be automatic or processed as needed. }\end{array}$ \\
\hline Money order & $\begin{array}{l}\text { A draft piece of paper issued by a bank, post office, or telegraph office authorizing } \\
\text { payment of a specified amount of cash from the issuing institution to the individual } \\
\text { named on the order. }\end{array}$ \\
\hline Travelers check & $\begin{array}{l}\text { A draft piece of paper issued by a bank or company and directing the issuer to pay a } \\
\text { specific amount of money in cash as instructed to a person or business. It is similar } \\
\text { to a check but works like cash and is protected against forgery, loss or theft. }\end{array}$ \\
\hline
\end{tabular}

Table 14: Definitions of Payment Instruments. 


\section{Response to Referee 1}

Thank you for your very helpful comments. My coauthors and I have edited the paper in response, which has substantially improved the paper. We describe our responses in this letter. Our letter follows the format of presenting your comments verbatim in italics, with our detailed response following each comment. We have added numbering to facilitate future discussion of these points. We have also added line numbers to our manuscript in order to facilitate references.

That said, the paper lacks key elements: (1) First, the authors need to substantially beef up the articulation of their specific research questions, and their contributions on both the methodological and empirical fronts, particularly for readers unfamiliar with payments research. These main points need to appear in brief in the abstract, and clearly in the introduction and the conclusion.

We have expanded the abstract to be more pointed about our contribution. Paragraphs 1, 4 and 5 of the paper provide the main points we hope to get across in the paper. As the introduction was stretching for 6 pages, we broke out the discussion of the policy background and literature review into a separate section, so the introduction is now 2.5 pages.

2) Second (but no less importantly), the exposition needs some extensive clarification. It is difficult for the reader to follow some of the basic explanations of the model, counterfactual experiments, and inference.

As we describe further below, we have improved the exposition in various places. Definitely let us know if there are parts that are still lacking.

(3) Finally, much of the inference from the estimation and counterfactuals needs better discussion to convince the reader of its validity. When the authors offer particular interpretations of specific findings, they need to bolster their explanations using cross-tabs in the data, comparisons with other papers, or benchmarks from outside sources, to convince the reader that their interpretations make sense.

In response to this issue, we have edited throughout the paper. For instance, we have added more references to raw data in interpreting our results. As examples, on page 26, line 2, we point out that the estimation results in Table 6 are similar to the raw data in Table 3. A similar point about adoption results appears at page 26, line 24. Also, we added a line at page 27 , line 7 to highlight that our results on age are similar to other papers in our "use-only" model but change in our "full model" when we account for adoption (the results change in ways we find believable). There is a similar point now at page 29 , line 1 .

In addition, we devoted substantial time to combing the existing literature for comparable results, and we provide references in the Results section whenever applicable. Examples new to this version are at page 27 , line 11 ; page 27 , line 19; page 29 , line 10 ; page 30 , line 5 ; 
page 31 , line 11 ; page 37 , line 1 ; page 37 , line 28 ; page 38 , line 3 ; page 38 , line 12 ; and page 42 , line 26 . Although existing results are usually not directly comparable due to the novelty of our approach, we often find supporting evidence on a qualitative level, or we can explain differences based on modeling differences.

Specific Comments

4. Abstract. The abstract needs to have more content about the contributions and the overall findings. What are the main takeaways the reader should get from the paper?

The abstract has been substantially overhauled.

5. The introduction is narrow (yet a bit too long), and does not emphasize the strongest contributions of the paper. The introduction should let the reader know (i) the primary research questions; (ii) why these questions are important; (iii) how (at a high level) the authors have attempted to answer these questions; (iv) the main research findings; and (v) the main implications or takeaways from these findings. To make the introduction effective, (i)-(iii) would best appear on the first page.

The introduction is rewritten to follow your suggestion. Your point (i) appears in the first line of the paper, with (ii) filling out the rest of the first paragraph. Paragraph 2 presents the data set. Part (iii) appears in paragraph 3, and then (iv) appears in paragraph 4 , and (v) appears in paragraph 5. We separated the discussion of the government policy and the literature review into a new section, in order to make the introduction more pointed. Thus, the current introduction is two-and-a-half pages long, substantially shorter than before.

6. Policy applications. The paper does not and really needs to - make clear the specific policy questions the model estimation and counterfactuals attempt to answer. For example, on $p$. 3, the second paragraph discusses that the authors separately consider changes to the use value and adoption cost of debit cards, and look at how that affects market shares for other instruments. I believe it's really just about instrument specific surcharges - you should just say that explicitly. This relates closely to the next point ...

We found attempting to describe the specifics of how we set up our counterfactual to be difficult in the new shorter and more-high level introduction. Thus, we now speak generally about determining substitution patterns in paragraph 3 of the introduction and leave the full presentation for the body of the paper. Also, we rewrote the first paragraph of the counterfactuals sections to explicitly link the policy changes we are interested in with the exact implementation in our model.

7. Use value vs. usage cost. What does the use value mean in the context of the industry? The policy question in this case is how consumers would respond to changes in a specific payment instruments usage cost (per-transaction fee or surcharge). As I read it, 
the authors have equated an increase in the usage with a decrease in the use value in the consumers utility function. If the question (and your estimation) is really about usage costs, then just state that explicitly throughout.

Examples of this confusion:

p. 3 "To evaluate substitution patterns for debit cards, we separately consider changes to the use value and adoption cost of debit cards..."

p. 21 "The former is attractive since we are specifically interested in distinguishing the effect of changes in adoption costs from use costs."

p. ${ }^{77}$ "We use our estimated model to assess consumer response to a change in the cost of using debit cards: the cost of use and the cost of adoption." But ... "To calculate a change in the usage value, we lower the mean utility of usage of debit cards enough to reduce debits overall share of usage by 1 percentage point" Its really unclear whats going on here. There also needs to be an explanation of why this is a reasonable exercise (e.g., why 30-31?).

You are clearly correct that we used the terms "use cost" and "use value" interchangeably, which is confusing for readers. In the current version, we use only the term "usage value," which corresponds best to the element of the model that it refers to. Also, in the model section, we now say explicitly that we refer to $\delta$ as the "usage value" and $\lambda$ as the "adoption cost," in order to draw attention to these definitions. See page 16, line 27 and page 17 , line 10. The sentences are: "Throughout the paper, we refer to $\delta_{i j c}$ as the usage value of instrument $j$ to consumer $i$ in context c." And "We refer $\lambda_{i j}$ as the adoption cost of $j$ to $i$, although $\lambda_{i j}$ is not restricted to be negative and could be an 'adoption benefit."'

Furthermore, we agree that it was difficult to follow exactly how we computed our counterfactual exercises. In response, we have added new paragraph that presents the exercise in mathematical symbols rather than prose. There is an unfortunate amount of notation to learn that is not re-used elsewhere in the paper, but it definitely lends clarity to an important part of the paper. The paragraph starts at page 34, line 17.

8. There is a separate important empirical question here about whether a decrease in use value (a decline in a consumer's utility from a good) is behaviorally equivalent to an increase in the usage cost. The behavioral and marketing literatures (and conversations with industry participants) indicate that it is not. It's important to make this distinction clear, and state accurately what the model assumes about the behavioral response to a usage value decrease versus a price increase.

We address this point at page 17 , line 16 . There are really two points in this paragraph. One is to make clear that we view usage value and adoption cost as capturing fees, and that we model changes in fees with changes in these values. The second point is how our 
model addresses the fact that consumers may not view pecuniary discounts and surcharges symmetrically, even if standard economics says they should. We place this paragraph in the model section, and we briefly repeat the first point at the beginning of 8.1 when we begin our discussion of counterfactuals. The paragraph is as follows:

We do not observe variation in prices of usage and adoption, but we assume those to be captured in the usage value $\delta_{i j c}$ and the adoption cost $\lambda_{i j}$. Thus, a change in fees can be modeled as a change in one of these values. An increased usage fee lowers $\delta_{i j c}$ whereas an increase in an adoption fee raises $\lambda_{i j}$. Similarly, we model a reduction in a rewards program as a reduction in $\delta_{i j c}$. In practice, consumers may not treat pecuniary benefits and costs symmetrically. For instance, consumers may value a dollar surcharge to using a card asymmetrically to a dollar subsidy to using a card. We do not observe fees or subsidies, so this is not an issue for us in estimation. Rather, we look at how demographic variables predict adoption and usage, so we capture the extent to which demographic variables, such as education, affect how consumers make choices. In our counterfactual analysis, we adjust $\delta_{i j c}$ and $\lambda_{i j}$ directly, so it may be interpreted either as a reduction in rewards or an increase in an explicit cost.

9. The credit function of credit cards. The paper largely (though not entirely) ignores the fact that credit cards have a credit function. The embedded credit function (as the authors are aware) makes them very different from debit cards in some key ways. The exposition and inference should be revised and adapted throughout to reflect this fact.

We have expanded on this issue in various places. See in particular page 16, line 4, which makes explicit how the model handles the fact that credit enables purchases, and page 26 , line 5 , which interprets the results along these lines.

10. Clarifications and inference. Here are passages where the exposition needs to be clarified, or the inference needs to be better developed, or both.

We greatly appreciate this remarkable list of editorial help. We certainly hope the current version reads better, including the parts that you did not highlight.

11. p. 3 - "We further find relatively small responses ... " Of what, to what?

This line did not survive the rewrite of our introduction. The idea appears in paragraph 4, which we hope is more clear.

12. $p 4$ - "Thus, the efficiency implications of a regulation ..." this is vague; just say what type of regulation you mean.

We agree that it is preferable to explicitly state the regulation rather than the vague reference we had in the previous version of the paper. The new version of the paper refers explicitly to the regulations we have in mind in the introduction. This happens in two places: page 2 , line 8 and page 4 , line 2 . For instance, the statement at page 2 , line 8 is: "More 
specifically, our research is motivated by recent regulation of the debit card interchange fee, further described below, that has the potential to make debit cards less attractive to consumers, either via usage charges or adoption charges. Recent regulation also allows merchants to surcharge for cards, which will most likely make credit less attractive." Note that these sentences come before our full discussion of the policies, which does not appear for two more pages, but we hope it is still a readable approach.

13 p. 5 (bottom) - "In contrast, our [sic] allows consumers to know more than the econometrician about usage." I agree that this is an important econometric innovation just explain briefly what this means here.

This sentence now reads: "Since consumers in the adoption stage perceive a portion of the terms in usage that are unobserved to the researcher, our model allows consumers to know more than the researcher about their usage when the consumers make their adoption decisions. We believe this is an attractive and realistic feature in the adoption of payments instruments." The part before the first comma is new. It appears at page 3 , line 8 .

14. p. 6 - "In contrast, we exploit the fact that we observe usage to pin down the substitutability (or complementarity) ..." Across what, exactly?

Now we write: "In contrast, we exploit the fact that we observe usage to pin down the substitutability (or complementarity) between payment instruments, .." The underlined part is new. This sentence appears at page 7 , line 4 .

15. p. 8 - "We use the weights to construct the tables ... and the summary statistics ..., but not to estimate the model parameters ... " Please note in all the tables which show nationally representative numbers and which do not.

We have adjusted all tables to indicate whether weighting is used.

16. $\quad$. 9 - Need to tighten up the explanation of the different payment instruments, particularly bill payment and "bank account deduction" (automated debit?).

In addition to editing the description of instruments (at page 9, line 7 ), we include Table 14 in the Appendix, which provides more detailed definitions of each instrument. The table is referenced at page 9 , line 6 .

17. p. 9-Footnote 9: Note that this is for the subset of low-income consumers who have bank accounts.

We have adjusted the last sentence of the footnote to acknowledge this point. It is now footnote 9 .

18. p. 10 "Essential" vs. "nonessential" retail - this terminology has the potential to mislead. In these categories, bar tabs are essential and replacement toilets are nonessential. It would help to either rename the categories (consumer nondurables vs. durables?) or at least note that the nomenclature is not perfectly reflective of consumers' actual needs. 
We have added a paragraph describing exactly how the survey asks consumers to distinguish between these concepts at page 11, line 12. The paragraph also acknowledges that the essential/non-essential terminology is imperfect. We struggled to come up with better terminology and left it as essential and non-essential.

19. p. 10 - "We see that cash and debit are popular for essential retail, whereas credit is relatively more popular for non-essential retail." The authors are very likely already aware of the economic reason for this, but it's not stated in the paper. Cash and debit are similar in their liquidity characteristics, and very different from credit. Withdrawing cash and conducting a debit transaction cause the consumer's deposit account balance to drop immediately, with no (immediate) possibility to "undo" the transaction. A credit card transaction has a built in credit function, so the consumer retains liquidity (via the deposit account) until the credit card balance is paid. Hence the tendency to use credit for larger, "lumpy" purchases.

Thanks for this - we have added a sentence that provides this interpretation of the results. It appears at page 26 , line 5 . Note that this line of our paper also responds to Point 9 above.

20. $p 11$ - It's a drawback of the paper that modeling transaction values is outside the scope of the paper - it would be best if the authors state this earlier in the paper.

We have added a sentence about this to introduction, at page 2, line 25.

21. $p 11$ - "Debit and credit look similar to each other, except for cost, where debit is better." This is a very intuitive finding - the authors could note that it's very consistent with the fact that about half (?) of credit card holders revolve a balance, so credit is more expensive for these consumers. (Have a look at the most recent Survey of Consumer Finances to get the exact proportion.)

We have added a footnote making this point. See footnote 12 .

22. $p$. 23 - "In addition to the 'full model' described above, we also provide estimates of the use stage alone ... "Restate what the "full model" is so the reader can follow easily.

Now the sentence reads: "In addition to the 'full model' described above (the model of both usage and adoption), we also provide estimates of a "use-only" model, which is the use stage alone, ignoring the adoption stage." The underlined part is new. This line appears at page 25 , line 8 .

23. p. 23 - "Wealthier households prefer credit cards." This is a pretty flat reading of the finding. It's surely not that wealthier households actually prefer credit cards more than less wealthy households. Rather, they're more likely to use them, all else equal, because they have them; they have higher credit limits (is this mentioned anywhere in the paper? It should be); they're less likely to carry a balance; and if they do carry a balance, they're less 
likely to do it for a long time or at a very high interest rate.

See our response to 24 below.

24. p. 23 - "Education has a large positive effect on credit card use ... perhaps because educated households are better able to manage a credit line." This is an overly simplistic story. Education is correlated with income (or parental income, which is unobserved), as well as a credit score, and whether or not the person carries a balance, so if there's going to be an interpretation here, it should be a more nuanced discussion.

These are excellent points to make, and we have added along these lines. In particular, we have added the following sentence in our discussion of the results at page 29, line 19: "The effects we find here could result from an inherent preference by high income, or high education consumers for credit over debit use, but presumably also reflect that these groups are likely to have higher reward cards, have higher limits, higher lifetime income, and are better at managing balances and fees."

25. p. 24- "Employment causes households to use debit and not credit, perhaps because they do not need the credit feature." This can't be the whole story - isn't it inconsistent with "wealthier households prefer credit"?

We agree that the employment result is difficult to interpret. We provide a somewhat more nuanced discussion in this version, appearing at page 29 , line 23 . The text is as follows:

"Even though we find that higher income consumers prefer credit cards, the relationship between employment and credit card use is the opposite: employed consumers use credit cards less than unemployed ones. This finding comes through both in the raw data and in the estimation. Perhaps these results reflect the conflicting roles that credit cards play in household finance; whereas income and employment makes credit cards more attractive and easier to manage, they also make the credit feature less necessary."

26. p. 27-33 - The whole counterfactuals section needs to be tightened up to make it extremely clear what the three experiments are, what policy questions they answer, and what the takeaways are. This is the most confusingly written section, and has the potential to be really sharp. There's good stuff here - it needs to be stated clearly, or it's not valuable.

As mentioned above, we have added a mathematical description of our policy experiment, starting at page 34 , line 17 . We have edited much of the section to try to make it more readable. For instance, we added a sign-post sentence reviewing the results so far at page 36 , line 12 .

27. p. 29 - Footnote 19. "One way to interpret the cost of debit adoption is to think about the cost of opening a checking account, although surprisingly debit card adoption is much lower than checking account adoption." Why is this surprising? This misses the point. 
Adopting a debit card is adoption of a technology, and is often conditional on opening a checking account. In contrast, opening a checking account is establishing a financial relationship. Adopting a debit card is not a necessity, in the sense that one can easily get by in the U.S. with cash, checks, and credit. In contrast, opening a checking account is a necessity in today's economy for all but the lowest-income households.

This line has been eliminated in the current version.

28. p. 31 - (Bottom paragraph) Is it possible in this survey to look for gender differences as well? They may be important empirically.

The survey does indeed ask about gender and we included gender in our usage equation interactions. We did not discuss it in the previous version. In the current version, we have added page 29 , line 29 , which says that males tend to prefer cash and particularly credit relative to debit or check.

Thanks again for all of your help.

Sincerely Yours,

Marc Rysman 
Response to Referee 2

Thank you for your very helpful comments. My coauthors and I have edited the paper in response, which has substantially improved the paper. This letter describes our response. Our letter follows the format of presenting the referee's comments verbatim in italics, with our detailed response following each comment. As your original letter used italics to represent exact quotes, we use a different font where you used italics. We have added paragraph numbering to facilitate future discussion of these points. We have also added line numbers to our manuscript in order to facilitate references.

1. This paper explores the important policy question of how consumers choose payment instruments and consequently, what the welfare costs of new regulations could be. It also introduces a new dataset on U.S. consumer payment use, which is also important for providing information on how consumers interact with the financial system. Finally, it uses appropriate econometric techniques to answer these questions.

2. Overall, the paper is very well written, uses reasonable econometric techniques, and answers an important policy question. While I found a few of the results at odds with intuition, most made sense. In the discussion, I would stress more the potential welfare costs of the regulations, and whether they would disproportionately affect lower-income households. Also, while probably difficult to do, the authors do not address whether the changes in use induced by the regulations would be efficiency improving in a broader sense.

Thanks for these complements. We have rewritten the introduction entirely in response to the comments of the other referee. We now discuss welfare implications in the introduction. See page 3, line 31. As you suggest, a full welfare evaluation of the policy is beyond the scope of our paper. We state this now in the introduction, at page 4, line 9. However, the conventional wisdom is that digital payments are more efficient that paper payments, which would imply that the changes in use induced by regulation reduce efficiency. We added a sentence making this point at page 4, line 4. The sentence reads "Since we find that making debit cards less attractive to consumers causes substitution towards paper products, the regulation may reduce the efficiency of the payments system."

3. My overall comment is that the authors should try to explore a little more deeply the potential welfare impact or discussion of possible regulations. Even if those regulations are not going to occur in the U.S., to the extent that it is possible to illustrate the differential impacts of flat fee versus surcharge regulations, that would be helpful.

In our paper, comparing flat fee versus surcharge regulation is captured by comparing changes in the usage value to changes in the adoption cost. In this version, we added a paragraph explaining that the welfare cost required to obtain a given change in market share is much higher for the case of changing adoption costs than usage values. That is 
because changing adoption costs has no effect on market shares unless consumers switch holdings, and it takes relatively large changes in adoption costs in order to get consumers to switch. This paragraph (which was a small footnote in the previous version) is at page 41, line 2 .

We were not sure how far to go with this. The next step in answering your question might be to draw up a figure like Figure 4 comparing the case of changes in usage value and adoption cost for different income levels (the figure currently looks only at the usage value case), but we felt the cases did not look different enough to warrant the extra space. But naturally, we are happy to include it if you are interested.

4. Specific comments are below.

5. "A separate settlement proposed in July, 2012 between merchants and Visa and MasterCard would allow merchants to surcharge different card products, rather than offer a discount (there is little difference between surcharging and discounting in standard economic models, but the difference appears important to industry participants.)" This is a classic "framing effect" problem, and could be treated as such with the "right" data.

We definitely agree that this would be an interesting issue to take on, as it has a role in both policy and industry perception. It is outside of this paper, but is on our minds as we develop future surveys. The footnote where this appears is now number 3

6. "In contrast, our allows consumers to know more than the econometrician about usage." Should either be our model or ours.

This line has been changed. It now appears at page 3, line 10.

7. Essential/non-essential retail. Please give examples.

The other referee also had this concern. We have added a paragraph describing exactly how the survey asks consumers to distinguish between these concepts at page 11, line 12 .

8. Table 3. If I am reading this table properly, it seems that consumers make on average 70 payments per month, which is an average of 2 per day. Is that high? About what we'd expect?

We have added a footnote 11 on this point. The footnote reads: "Table 3 implies that the total number of transactions in a month is 68.6. This number is difficult to verify in other data sets. Interestingly, a recent diary-based survey of payment habits administered to the same population found a similar total number of transactions. For more on the Diary of Consumer Payment Choices, see Shy and Stavins (2014)."

9. "We assume the rating of set-up cost affects adoption, but does not otherwise affect usage. We assume that the rest of the characteristics affect usage but not otherwise adoption. Thus, if we see that consumers who find an instrument easy to use are particularly likely to adopt, than our exclusion restriction imposes that usage has a causal effect on adoption." 
This line has been edited, and it appears at page 14, line 3 .

10. Table 5. Would report lower triangle of table.

We now report only the lower triangle. It is Table 5 in the current version.

11. "Also, every bundle $b_{i}$ contains option $j=0$, the option to not make a purchase." I am a little unclear on the interpretation of this sentence. The previous sentence says that the choice is over bundles of instruments, and this sentence states the choice is over purchasing or not purchasing. Please clarify.

The consumer picks a bundle of payment instruments in the first stage. In the second stage, the consumers faces a series of payment opportunities. At each opportunity, the consumer chooses from the selected bundle which payment instrument to use, or to not take advantage of the opportunity, which is formally denoted as choosing $j=0$. We have added the following line to the discussion at page 15, line 12: "At each payment opportunity $l$, the consumer chooses from $b_{i}$ which payment instrument to use, which may be the choice to forgo the payment opportunity." Just past that, we write "The consumer can also choose not to use an opportunity, and thus make no payment, denoted as choosing $j=0$."

12. "In practice, we assume that the number of payment opportunities $L$ is 436 per month, about 14 per day, constant across all consumers. This number is above what we observe for any consumer in the data set, and well above the average number of transactions." I am not sure what is the importance of the 436. Please clarify.

We have added footnote 13 on this issue. The footnote reads: "The choice of $L$ is analogous to selecting the size of the potential market in typical discrete choice models, such as Berry, Levinsohn, and Pakes (1995) and Nevo (2001). In many data sets, we observe market shares among the available products but we do not observe how many people might have purchased but selected not to. In order to model the choice not to purchase, we must make an assumption on the potential market. In practice, the assumption on the potential market primarily affects the constant term, but not the other parameters."

Incidentally, we changed in this version to using $L=390$, or 13 per day.

13. The authors could estimate the Dubin-McFadden model to show how the restrictions imposed by their model are critical for understanding the payment choice decision.

Schuh and Stavins (2013) estimate a Heckman selection model separately for each payment instrument on our same data set. I believe this is what you have in mind. We have added a paragraph contrasting our results, on page 33, line 15.

14. "That is, adopting one payment instrument does not raise or lower the costs of adopting another payment method." This is a critical assumption in order to model bundles. However, it is not necessarily true in the case of payment instruments associated with a bank account. That is, the main decision is whether to hold a bank account. Then, associated 
with that decision is the decision to adopt multiple payment instruments. Presumably, once the consumer has a bank account, then all other decisions follow. I understand that the sample is based on only those consumers that hold a bank account; however, it should likely be mentioned that this decision is the first one.

This is definitely a good point to raise. We felt our paper was reasonably strong on this point since, as you say, we do not model the adoption of bank accounts. We added the following footnote (numbered 18) to this part of the text, but let us know if it does not meet your expectations: "Our approach would be more problematic if we were also modeling the adoption of bank accounts. Naturally, adopting a bank account makes it easier to adopt a credit card (since consumers typically pay a credit card bill out of a bank account), a debit card, on-line bill-pay, and others. However, we study only consumers that hold bank accounts."

15. Table 7, demographic results. I found some of these demographic results surprising, especially in the full sample. Specifically, the result that age is positively correlated with debit card use and credit is at odds with other results. I understand that the estimation method controls for all sorts of potential selection biases; still, this result seems at odd with intuition.

This is a tricky issue in interpreting our results. In fact, although there are indeed positive coefficients on age in debit and credit, that is due to the fact that older consumers make more transactions overall. The positive coefficient does not, by itself, imply that age is positively correlated with debit card and credit card relative to the use of other instruments. Rather, we should focus on which coefficients are most positive to determine which instruments are used relatively more. In this case, that is check, which probably conforms to your prior belief. This issue is important for readers to understand so we added the following paragraph, specifically highlighting the age results, at the beginning of the discussion at page 26 , line 26 .

"Table 7 presents the effect of each demographic variable on each payment instrument in the use equation. The coefficients represent the extra preference (positive or negative) that a particular demographic group places on a particular payment instrument. In interpreting this table, keep in mind that the parameters are relative to the outside option of not making a transaction. So for instance, consider the variable age. If all the coefficients were positive and of the same size, that would tell us that older consumers make more transactions, but prefer all instruments with the same relative proportions as younger consumers. That is, a positive coefficient on age for one instrument does not mean that older consumers use that instrument more than other instruments. The size of the coefficient must be compared to the coefficient on age for other instruments." 
16. Figure 4, welfare results. From a policy perspective, this chart is probably the most important. It would be good if the authors could provide more perspective on what these percentage estimates mean, and a dollar value associated with them. How these dollar values compare to the overall fee revenue or surcharge would be important to understand.

We agree that it would be important to place dollar values on the cost-benefit side of the intervention. Unfortunately, it is a limitation of our context that the survey data does offer any variation in monetary cost across payment instrument (and across demographic groups, such as income level). Therefore we can't identify the dollar change that would correspond to shifts in welfare we observe directly from our data.

However, in this version of the paper, we try to make use of the existing literature to make progress on this issue. We rely on some existing research to say that the change in the price of debit that would lead to a $1 \%$ decline in debit usage is 3.6 cents. Since we compute in our model the utility change in debit that would lead to a $1 \%$ decline, we have the price change that corresponds to a utility change, and thus we can infer the marginal utility of income. We can then divide welfare by this parameter to convert welfare to dollar numbers. We find that a 3.6 cent increase in the per-usage price of debit generates an overall welfare loss of about 78 cents per month among debit card users. This discussion starts at page 41, line 9 .

Sincerely Yours,

Marc Rysman 
Dear Jim,

Thank you for your positive response to our paper, and thanks greatly for the very helpful comments from you and the referees. My coauthors and I have edited the paper in response, which has substantially improved the paper. This letter describes our response. Our letter follows the format of presenting your comments verbatim in italics, with our detailed response following each comment. We have kept your numbering to facilitate future discussion of these points. We have also added line numbers to our manuscript in order to facilitate references. In addition, we have attached two letters, one for each referee, detailing our specific responses to each of their concerns.

Thank you for submitting your manuscript to the RAND Journal of Economics. I have now heard back from two reviewers of the manuscript and have closely read it myself. Both reviewers like the paper and recommend requesting a revision. Having read the paper myself, I agree with their assessments. Payment instrument choice decisions are in several ways natural for the discrete- choice demand-estimation toolkit you employ. The specific structure you have added to the general framework is quite sensible given the institutional details of the market. There are also an important set of policy questions surrounding payment instrument choice that makes high-quality quantitative analysis of it both interesting and useful.

Thanks for these kind words!

Both of the referees, as well as I, still have some concerns that we would like to see addressed in a revision, should you choose to submit one. I ask you give priority to the following items.

1. The paper needs to highlight its key research goals more clearly. (This is related to R1s comment about articulation of research questions and some of R2s comments as well.) Do you see the papers primary purpose as presenting a general methodology for payment instrument choice, with the quantitative analyses in the paper being example applications of this method? Or do you instead see the paper as primarily addressing specific policy questions about debit and credit card fees, where you have constructed an apparatus to analyze those questions (recognizing that this apparatus may also be useful for other related research questions)? The paper as written now seems to straddle these two structures. I dont have a strong preference which angle you want to take, but I do think you should choose just one conceptual structure and then write the paper in a way that makes this choice clear. As $R 1$ notes, this clarity should be apparent within the introduction section.

We have entirely rewritten our introduction, following the comments of Referee 2 . We have emphasized the policy relevance of the paper, although we certainly still highlight the model as a method for thinking about payment choice. Please also see our response to 
Referee 1 on this issue, in comment 5.

2. Perhaps I missed it, but it wasn't clear from the discussion in the paper what was assumed during estimation about the number and composition of payment contexts a household faced. Are you assuming every household faces the average distribution reflected in Table 3, or are you pulling specific draws from the observed distribution in the data in your algorithm? In other words, what is the distribution of contexts you are fitting in the simulated observations? It seems like fitting the entire distribution rather than the average would be preferable.

At every payment opportunity, the consumer may choose among the entire set of payment contexts. All consumers face every context at every payment opportunity. Household preferences will lead to a distribution of choices, the average of which is reflected in Table 3 , but there is no sense in which consumers are restricted in their choices. We have added the following line in the description of the model at page 15, line 20: "At each payment opportunity, each consumer selects from one of the seven contexts - all contexts are always available. The consumer can also choose not to use an opportunity, and thus make no payment, denoted as choosing $j=0 . "$

3. You should report more information about the fit of the model. It would be good see how well it does predicting choices in a hold-out subsample that is not used in the estimation.

We find that the level of fit of the model is quite decent, with R2 of $50.5 \%$ when looking at the predictions of "market shares" of payment instrument, by context, in the usage stage. On a set of 100 randomly selected sub-samples, the R2 has median of $50.4 \%$ and standard deviation of $2.04 \%$. We discuss this at page 33 , line 9

4. Credit cards have a fundamentally different feature from the other payment instruments (credit extension, of course). As the referees point out, the model does not treat this feature directly. How would we expect credit extension effects to show up? If the credit extension benefit is the same for all transactions of a given context, then it seems it will just show up in $\delta_{i j c}$. This seems unlikely, however. Even within a given context, credit is quite likely to be more valuable for certain types of purchases for certain types of people. For example, I expect that credit is more useful for larger (relative to income) purchases within a context. I don't think you necessarily need to modify the model to account for such features, but there should be some discussion of how credit extension benefits would be interpreted by the model.

You are correct that if credit extension led consumers to make proportionally more of all transactions with credit cards, than $\delta_{i j c}$ would be higher for all contexts $c$, whenever $j=$ credit card. If credit lines primarily led to one type of transaction, for instance nonessential retail transactions, then we would expect $\delta_{i j c}$ to be higher for $j=$ credit card and 
$c=$ non-essential retail.

Referee 1 brings up similar points in Comment 9. We have expanded on this issue in various places. See in particular page 16 , line 4 , which makes explicit how the model handles the fact that credit enables purchases, and page 26 , line 5 , which interprets the results along these lines.

5. If possible, put more context on the counterfactual changes you impose in Section \%. Is a 1 percentage point drop in debit cards market share supposed to simulate something in particular, a certain-sized fee change, etc.?

It is unfortunately difficult to map these numbers into dollar terms. A 1 percentage point drop is meant to be "small drop," in order to approximate an elasticity (which would be an infinitesimally small drop). We make this point in the paper now at page 35 , line 3 .

In this version of the paper, we also make an attempt at putting dollar values to our welfare findings by using measures of dollar-valued substitution results for debit that are in the existing literature. Previous research finds that a 3.6 cent change in the price of debit would lead to a $1 \%$ drop in the debit market share. In our context, that would imply that a 3.6 cent per-use increase in the price of debit would cause 78 cents in welfare loss for debit users. This discussion appears at page 41, line 9 . This number requires some strong assumptions, but it does provide a dollar value as you and the referee wished.

6. Please report some information regarding the statistical size of the changes observed in the counterfactuals. You should be able to run counterfactual calculations using parameters drawn from their distributions rather than just using their point estimates.

Thank you for this suggestion. Indeed, on some of the bar graphs the differences seem so close that it is hard to tell if they are statistically different. In this new draft, we improve the presentation of results by adding confidence bounds directly on the bar plots. Whenever two experiments are shown, we add bounds one of them - otherwise, the graph becomes too messy. Having one set of bounds is sufficient to visually establish the significance of results.

7. The referees have both offered several additional, detailed, and sensible suggestions for the paper (especially regarding the counterfactuals) that should be addressed whenever practical.

We have responded in detail in our other letters.

I cannot make any promises at this point, but a revision that effectively addresses these issues will receive close consideration for publication in RAND. Please let me know if you have any questions.

Thanks for your consideration!

Sincerely Yours, Marc Rysman 